
\title{
Besearch S Surare \\ Design and Analysis of a Novel Schönflies Motion Parallel Robot with Full Cycle Rotation
}

\author{
Luquan Li \\ Beijing Jiaotong University \\ Yuefa Fang ( $\nabla$ yffang@bjtu.edu.cn ) \\ Beijing Jiaotong University \\ Lin Wang \\ Beijing Jiaotong University \\ Jiaqiang Yao \\ Beijing Jiaotong University
}

\section{Original Article}

Keywords: Single-loop parallel robot, Schönflies Motion, Virtual work principle, Dynamics

Posted Date: July 23rd, 2021

DOI: https://doi.org/10.21203/rs.3.rs-742385/v1

License: (9) This work is licensed under a Creative Commons Attribution 4.0 International License. Read Full License 


\section{Title page}

\section{Design and Analysis of a Novel Schönflies Motion Parallel Robot with Full Cycle Rotation}

Lu-Quan Li, born in 1994, is currently a PhD candidate at School of Mechanical, Electronic and Control Engineering, Beijing Jiaotong University, China. He received his bachelor's degree from Beijing Jiaotong University, China, in 2017. His research interests include parallel mechanism design, walking robot.

E-mail: 18116017@bjtu.edu.cn

Yue-Fa Fang, born in 1958, is currently a professor at School of Mechanical, Electronic and Control Engineering, Beijing Jiaotong University, China. His main research interests include robotic mechanism, parallel robot and mechanical design.

E-mail: yffang@bjtu.edu.cn

Lin Wang, born in 1995, is currently a PhD candidate at School of Mechanical, Electronic and Control Engineering, Beijing Jiaotong University, China.

E-mail: 18116022@bjtu.edu.cn

Jia-Qiang Yao, born in 1995, is currently a PhD candidate at School of Mechanical, Electronic and Control Engineering, Beijing Jiaotong University, China.

E-mail: 20116013@bjtu.edu.cn

\section{Corresponding author: Yue-Fa Fang E-mail: yffang@bjtu.edu.cn}




\title{
ORIGINAL ARTICLE
}

\section{Design and Analysis of a Novel Schönflies Motion Parallel Robot with Full Cycle Rotation}

\author{
Lu-Quan Li • Yue-Fa Fang $\bowtie \bullet$ Lin Wang • Jia-Qiang Yao
}

Received June xx, 202x; revised February xx, 202x; accepted March xx, 202x

(C) Chinese Mechanical Engineering Society and Springer-Verlag Berlin Heidelberg 2017

\begin{abstract}
Due to the complex structures of multi-limbed parallel robots, conventional parallel robots generally have limited workspace, complex kinematics, and complex dynamics, which increases the application difficulty of parallel robot in industrial engineering. To solve the above problems, this paper proposes a single-loop Schönflies motion parallel robot with full cycle rotation, the robot can generate Schönflies motion by the most simplified structure. The novel Schönflies motion parallel robot is a two-limb parallel mechanism with least links and joints, and each limb is driven by a 2-degree of freedom (DOF) cylindrical driver (C-driver). The full cycle rotation of the output link is achieved by "...R-H..." structure, where the revolute (R) and helical $(\mathrm{H})$ joints are coaxial. Mobility, kinematics, workspace and singularity analysis of novel Schönflies motion parallel robot are analyzed. Then, dynamic model is formulated based on the principle of virtual work. Moreover, a pick-and-place task is implemented by proposed Schönflies motion parallel robot and a serial SCARA robot, respectively. The simulation results verify the correctness of the theoretical model. Furthermore, dynamics performances of Schönflies motion parallel robot and serial SCARA robot are compared, which reveal the performance merits of proposed Schönflies motion parallel robot.
\end{abstract}

Keywords: Single-loop parallel robot - Schönflies Motion • Virtual work principle $•$ Dynamics

\section{Introduction}

Schönflies motion robot with three translations $(T)$ along three orthogonal independent directions and one rotation $(R)$ around one fixed direction is very widely applied in industry, especially for pick-and-place and assembly task. The first Schönflies motion robot developed by Furuya [1] is the most typical serial Schönflies motion robot and was

$\triangle$ Yue-Fa Fang

yffang@bjtu.edu.cn first used in industry [2]. After the Stewart-Gough platform [3] was built, the merits of parallel robot are revealed by researchers, parallel robot has high stiffness, low inertia, high positional accuracy, fast speed, fast acceleration and large loading capacity over their serial counterpart $[4,5]$. Then, researchers started to study Schönflies motion parallel robot with closed-loop structure. A large number of parallel mechanisms with Schönflies motion are designed by researchers, such as, a kinematically redundant Schönflies motion parallel robot with five-limbs [6], four-limbed Schönflies motion parallel robots [7-18], Pantopteron-4 with three pantograph linkages [19], two-hybrid-limbed Schönflies motion parallel robots [20-22], two-limbed Schönflies motion parallel robots [12, 23-30] and Schönflies motion parallel robot with parallelogram linkages [31, 32].

Two-limbed Schönflies motion parallel robots only have two limbs and are single-loop structure, their structures are simplified, hence they have the potential to reduce to links interference and closed-loop constraints and geometrical constraints to increase workspace and reduce the difficulty of solution kinematics and dynamics [33-35]. For two-limbed Schönflies motion parallel robots, each limb needs two 1-DOF joints as the actuated joints, such as in Refs. [12, 23-25], although one actuated joint can be mounted on a fixed base or near the base-mounted, there are always at least one motor is moving in a limb, which increases the moving mass and inertia and affects the performances of the parallel robots. To avoid moving motor in a limb, the two-limbed Schönflies motion parallel robots, whose motors are mounted on a fixed base, were designed by linkages [36] or C-drivers [37-39].

The rotational capability of most of these Schönflies motion parallel robots is limited, usually less than $90^{\circ}$. For industrial application, the large rotational capability even 
full circle rotational capability is necessary. Researchers are keeping trying to design Schönflies motion parallel robots with large rotational capability or full cycle rotation by different ways. For examples, some researchers added gears or belt/pulley devices on the moving platform to construct Schönflies motion parallel robots with large rotational capability or full cycle rotation $[7,8,14,15,24$, 40], but which leads to increased system complexity. Lee et al. [26, 27] designed isoconstrained parallel robots with full cycle rotation by using two coaxial $\mathrm{H}$ joints, which provides a new idea for design parallel robots with full cycle rotation. Gosselin [20] and Arian [21] designed SMGs with infinite tool rotation by linkage and helical pair.

In this paper, a single-loop Schönflies motion parallel robot is designed, the novel Schönflies motion parallel robot has the most simplified structure, large operational space, and full cycle rotation. Section 2 introduces the novel Schönflies motion parallel robot, and its structure is compared with that of existing Schönflies motion parallel robots. The kinematics are analyzed, and the Jacobin matrixes are derived in Section 3. Section 4 investigates the workspace and singularities of the single-loop Schönflies motion parallel robot. Based on the principle of virtual work, the dynamics model is formulated in Section 5. Moreover, a pick-and-place task is implemented by the presented Schönflies motion parallel robot and typical serial SCARA robot, respectively; and dynamic performances of two robots are compared in Section 6 . Finally, conclusions are outlined in Section 7.

\section{Configuration of single-loop Schönflies motion parallel robot}

As shown in Figure 1(a), the Schönflies motion parallel robot is composed of a fixed base, two serial limbs, i.e., a $\underline{\mathrm{CRH}}$ chain and a $\underline{\mathrm{CRR}}$ chain, where the underlined symbols represent the actuated joints, and an output link, namely, it's a $\underline{C} R H-R R \underline{C}$ single-loop parallel robot. The output link is connected to two limbs by an $\mathrm{R}$ joint and an $H$ joint, where the $R$ joint and $H$ joint are coaxial, this structure makes the output link to full circle rotate. To illustrate that the proposed single-loop Schönflies motion parallel robot possesses most simplified structure, Table 1 lists the configuration characteristics of existing typical Schönflies motion generator, include the numbers of links, single-DOF joints and closed-loops and so on. Compared with other Schönflies motion parallel robots, proposed Schönflies motion parallel robot has the least links and single-DOF joints, and most simplified structure, and it possesses full cycle rotation.

For novel Schönflies motion parallel robot, i.e., $\underline{\mathrm{C} R H}-\mathrm{RR} \underline{\mathrm{C}}$ parallel robot, each limb is driven by a $\mathrm{C}$-driver. As shown in Figure 1(b), the C-driver is composed of two parallel right-hand and left-hand screws, gear sets and linear guides. The $\mathrm{C}$-driver generates cylindrical motion based on the cylindrical differential mechanism. It can generate independent rotation and translation along the concentric axis.

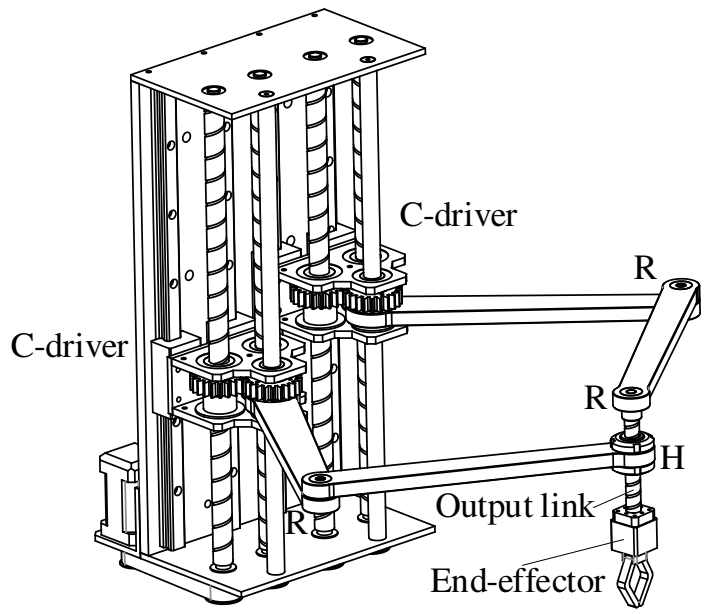

(a)

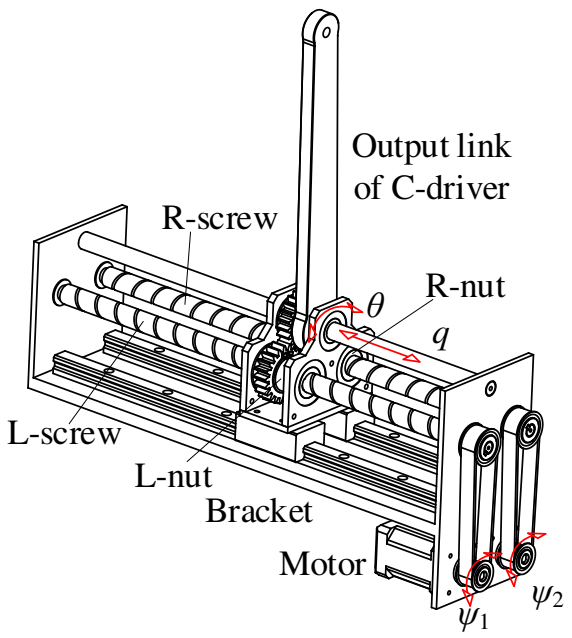

(b)

Figure 1 Configuration of Schönflies motion parallel robot: (a) CAD model; (b) C-driver.

\section{Kinematics}

\subsection{Mobility analysis}

The mobility of proposed Schönflies motion parallel robot is analyzed by Lie group Theory [41, 42]. Prior to analyze, relative displacement subsets are listed as follow: 
Table 1 Comparison of the existing $3 T 1 R$-parallel robot.

\begin{tabular}{lcccccc}
\hline & \multicolumn{7}{c}{ Numbers } \\
\cline { 2 - 7 } Mechanisms & Limbs & Links & $\begin{array}{c}\text { Single-DOF } \\
\text { joints }\end{array}$ & $\begin{array}{c}\text { Closed } \\
\text { loops }\end{array}$ & $\begin{array}{c}\text { Full } \\
\text { rotation }\end{array}$ & $\begin{array}{c}\text { Moving } \\
\text { motors }\end{array}$ \\
\hline SPARA[6] & 5 & 15 & 47 & Multi & 1 & 0 \\
\hline I4 [8] & 4 & 17 & 55 & Multi & 1 & 0 \\
H4 [10] & 4 & 16 & 46 & Multi & 0 & 0 \\
Par4 [7, 40] & 4 & 19 & 56 & Multi & 1 & 0 \\
Heli4 [9] & 4 & 16 & 54 & Multi & 1 & 0 \\
4-PRUR [12] & 4 & 14 & 20 & Multi & 0 & 0 \\
SCARA parallel robot [20] & 4 & 13 & 16 & Multi & 1 & 0 \\
SCARA parallel robot [21] & 4 & 14 & 19 & Multi & 1 & 0 \\
Pantopteron-4 [19] & 3 & 30 & 37 & Multi & 0 & 0 \\
2-(PRR)2RH [22] & 2 & 14 & 16 & Multi & 1 & 0 \\
Dual4 [23] & 2 & 7 & 9 & Single & 1 & 2 \\
2-PRPU [24] & 2 & 8 & 10 & Single & 0 & 2 \\
2-CRRH [39] & 2 & 8 & 10 & Single & 1 & 0 \\
CRH-RRC & 2 & 6 & 8 & Single & 1 & 0 \\
\hline
\end{tabular}

Note: In Table 1, in "Full rotation" column, "1" represents that the mechanism has full cycle rotation, and " 0 " represents that the mechanism does not have full cycle rotation.

$\{R(N, \boldsymbol{w})\}$ displacement subgroup of rotation about the axis determined by the unit vector $\boldsymbol{w}$ and point $N$.

$\{H(N, \boldsymbol{w}, p)\}$ displacement subset of helical motion about the axis determined by the unit vector $\boldsymbol{w}$, point $N$ and pitch $p$.

$\{C(N, \boldsymbol{w})\}$ displacement subset of cylindrical motion about the axis determined by the unit vector $\boldsymbol{w}$ and point $N$

$\{T\}$ displacement subset of three translational motion about along three orthogonal directions.

$\{X(\boldsymbol{w})\}$ Schönflies motion subgroup with unit vector $\boldsymbol{w}$ defining the direction of its rotational axis.

For a serial limb, the displacement subgroup (DSG) or displacement submanifold (DSM) of the end link equals to the product of the DSGs/DSMs associated with included joints. Based on the product operation, the DSG $\left\{D_{\mathrm{L} i}\right\}$ associated with the end link of the two limbs can be derived as

$$
\left\{\begin{array}{l}
\left\{D_{\mathrm{L} 1}\right\}=\left\{C\left(N_{1}, \boldsymbol{w}\right)\right\}\left\{R\left(N_{2}, \boldsymbol{w}\right)\right\}\left\{H\left(N_{3}, \boldsymbol{w}, p\right)\right\} \\
=\{T\}\{H(N, \boldsymbol{w}, p)\}=\{X(\boldsymbol{w})\} \\
\left\{D_{\mathrm{L} 2}\right\}=\left\{C\left(A_{1}, \boldsymbol{w}\right)\right\}\left\{R\left(A_{2}, \boldsymbol{w}\right)\right\}\left\{R\left(A_{3}, \boldsymbol{w}\right)\right\} \\
=\{T\}\{R(A, \boldsymbol{w})\}=\{X(\boldsymbol{w})\}
\end{array}\right.
$$

The DSG associated with the output link in a single-loop chain is the intersection of the DSGs associated with the end link of the two limbs. Then, according to intersection operation, the DSG associated with the output link of the proposed Schönflies motion parallel robot is derived as

$$
\begin{aligned}
\left\{D_{\mathrm{O}}\right\} & =\left\{D_{\mathrm{L} 1}\right\} \cap\left\{D_{\mathrm{L} 2}\right\} \\
& =\{T\}\{H(N, \boldsymbol{w}, p)\} \bigcap\{T\}\{R(A, \boldsymbol{w})\} \\
& =\{X(\boldsymbol{w})\}
\end{aligned}
$$

Hence, the output link of the proposed Schönflies motion parallel robot can generate three translations and one rotation around axis $\boldsymbol{w}$.

\subsection{Position analysis}

For a C-driver, the relationships between outputs $\theta$ and $q$ of the $\mathrm{C}$-driver can be written as

$$
\left\{\begin{array}{l}
\theta=k \psi_{1}-2 \pi q / p_{1} \\
\theta=k \psi_{2}-2 \pi q / p_{2}
\end{array}\right.
$$

where $\psi_{1}$ and $\psi_{2}$ are the rotation of the motors connected to the two screws; $k$ is the transmission ratio of synchronous belt transmission; $p_{1}$ and $p_{2}$ are the pitches of the two screws, respectively. The outputs $\theta$ and $q$ can be derived as

$$
\left[\begin{array}{l}
\theta \\
q
\end{array}\right]=\frac{k}{p_{1}-p_{2}}\left[\begin{array}{ll}
p_{1} & -p_{2} \\
\frac{-p_{1} p_{2}}{2 \pi} & \frac{p_{1} p_{2}}{2 \pi}
\end{array}\right]\left[\begin{array}{l}
\psi_{1} \\
\psi_{2}
\end{array}\right]
$$

Obviously, the pitches of two screws must be unequal, i.e., $p_{1} \neq p_{2}$. As illustrated in Eq. (4), the rotation $\theta$ and translation $q$ are independent.

The inputs $\psi_{1}$ and $\psi_{2}$ can be derived as

$$
\left[\begin{array}{l}
\psi_{1} \\
\psi_{2}
\end{array}\right]=\frac{1}{k}\left[\begin{array}{ll}
1 & 2 \pi / p_{1} \\
1 & 2 \pi / p_{2}
\end{array}\right]\left[\begin{array}{l}
\theta \\
q
\end{array}\right]
$$

The kinematic schematic of the proposed Schönflies motion parallel robot is shown in Figure 2. The vector loop closure equations can be derived as

$$
-(-1)^{i} l \boldsymbol{u}+q_{i} \boldsymbol{w}+l_{i 1} \boldsymbol{a}_{i}+l_{i 2} \boldsymbol{b}_{i}-(-1)^{i}\left(l_{i 3}+l_{i 4}\right) \boldsymbol{w}=\boldsymbol{t}
$$

where vector $\boldsymbol{u}=[1,0,0]^{\mathrm{T}}, \boldsymbol{v}=[0,1,0]^{\mathrm{T}}$ and $\boldsymbol{w}=[0,0,1]^{\mathrm{T}}$ are the unit vectors parallel to $X-, Y$ - and $Z$-axes, respectively, $\boldsymbol{a}_{i}=\left[\begin{array}{lll}s \theta_{i 1}, & c \theta_{i 1}, & 0\end{array}\right]^{\mathrm{T}}$ and $\boldsymbol{b}_{i}=\left[s \theta_{i 2}, c \theta_{i 2}, 0\right]^{\mathrm{T}}$ are the unit directional vectors of links $\mathrm{A}_{i} \mathrm{~B}_{i}$ and $\mathrm{B}_{i} \mathrm{C}_{i}$, respectively; symbols $\mathrm{s}$ and $\mathrm{c}$ denote the cosine and sine functions, respectively; $q_{i}$ and $\theta_{i}$ represent the outputs of the $\mathrm{C}$-driver associated with the $i$ th limb, respectively; $l_{i 1}$ and $l_{i 2}$ are the lengths of links $\mathrm{A}_{i} \mathrm{~B}_{i}$ and $\mathrm{B}_{i} \mathrm{C}_{i}$. To facilitate parameter 
description, the $\mathrm{R}$ joint at position point $\mathrm{C}_{2}$ can be regarded as a zero pitch $\mathrm{H}$ joint. $l_{i 3}+l_{i 4}$ is the distance from the position point $\mathrm{C}_{i}$ of joint to reference point $\mathrm{P}$, therein $l_{i 3}$ is the displacement of $\mathrm{H}$ joint, $l_{i 4}$ is fixed distance. $l$ is the distance between the axis of $\underline{\mathrm{C}}$ joint and Z-axis. $\boldsymbol{\gamma}=\gamma \boldsymbol{w}$ is rotation displacement of the output link, here, anti-clockwise is positive. The location vector of the reference point $\mathrm{P}$ of the output link $\boldsymbol{t}=[x, y, z]^{\mathrm{T}}$ is described in the fixed frame $\{\boldsymbol{G}\}: O-X Y Z$. The pose and position of the output link can be described as $\boldsymbol{P}=[\boldsymbol{t} \gamma]^{\mathrm{T}}$ in the fixed frame $\{\boldsymbol{G}\}$.

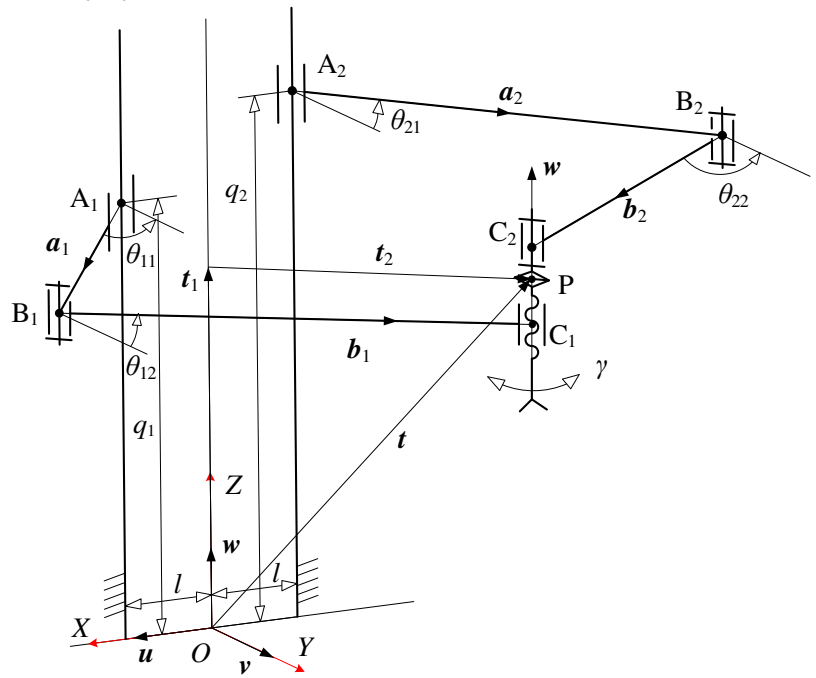

Figure 2 Kinematic schematic of $\underline{C R H-R R} \underline{C}$ mechanism.

According to the configuration characteristics, the location vector of the reference point $\mathrm{P}$ of the output link can be written as

$$
\boldsymbol{t}=\boldsymbol{t}_{1}+\boldsymbol{t}_{2}
$$

where $\boldsymbol{t}_{1}=[0,0, z]^{\mathrm{T}}$ and $\boldsymbol{t}_{2}=[x, y, 0]^{\mathrm{T}}$.

Based on Eq. (7), the Eq. (6) can be derived as

$$
\begin{array}{r}
-(-1)^{i} l \boldsymbol{u}+l_{i 1} \boldsymbol{a}_{i}+l_{i 2} \boldsymbol{b}_{i}=\boldsymbol{t}_{2} \\
q_{i} \boldsymbol{w}-(-1)^{i}\left(l_{i 3}+l_{i 4}\right) \boldsymbol{w}=\boldsymbol{t}_{1}
\end{array}
$$

Squaring both sides of Eq. (8) derives as

$$
\left(\boldsymbol{t}_{2}+(-1)^{i} l \boldsymbol{u}\right)^{2}-2 l_{i 1}\left(\boldsymbol{t}_{2}+(-1)^{i} l \boldsymbol{u}\right) \cdot \boldsymbol{a}_{i}+l_{i 1}{ }^{2}=l_{i 2}{ }^{2}
$$

Substituting $\boldsymbol{a}_{i}=\left[s \theta_{i 1}, c \theta_{i 1}, 0\right]^{\mathrm{T}}$ into Eq. (10), and based on trigonometric functions, the Eq. (10) can be translated into

$$
\text { where } \quad k_{i}=\tan \left(\theta_{i 1} / 2\right) ; \quad \mathrm{A}_{i 1}=-2 l_{i 1}\left(\boldsymbol{t}_{2}+(-1)^{i} l \boldsymbol{u}\right) \bullet \boldsymbol{u} \text {, }
$$
$\mathrm{A}_{i 2}=-2 l_{i 1}\left(\boldsymbol{t}_{2}+(-1)^{i} l \boldsymbol{u}\right) \cdot \boldsymbol{v}, \mathrm{A}_{i 3}=\left(\boldsymbol{t}_{2}+(-1)^{i} l \boldsymbol{u}\right)^{2}+l_{i 1}{ }^{2}-l_{i 2}{ }^{2}$. Then, the rotation outputs $\theta_{i 1}$ of the $\mathrm{C}$-driver associated with the $i$ th limb can be derived as

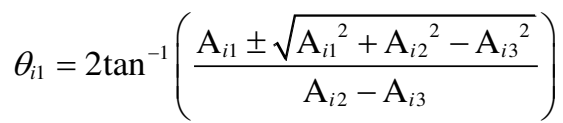

According to Eq. (8), the unit directional vectors of link
$\mathrm{B}_{i} \mathrm{C}_{i}$ can be written as

$$
\boldsymbol{b}_{i}=\left(\boldsymbol{t}_{2}+(-1)^{i} l \boldsymbol{u}-l_{i 1} \boldsymbol{a}_{i}\right) / l_{i 2}
$$

The angle between link $\mathrm{B}_{i} \mathrm{C}_{i}$ and $Y$-axis (i.e., the angles of the passive joints at points $\mathrm{B}_{i}$ ) are derived as

$$
\theta_{i 2}=\arccos \left(\boldsymbol{b}_{i} \cdot \boldsymbol{v}\right)
$$

The relationships between $\gamma$ and $\theta_{i 2}$ can be written as

$$
\frac{\boldsymbol{\gamma}-\boldsymbol{\theta}_{i 2}}{2 \pi} p_{i 3}=l_{i 4} \boldsymbol{w}
$$

where $p_{i 3}$ is the pitch of the screw of the output link, especially, $p_{23}=0, \boldsymbol{\theta}_{i 2}=\theta_{i 2} \boldsymbol{w}$. Based on Eq. (9) and combining Eq. (15), the translation outputs $q_{i}$ of the $\mathrm{C}$-driver associated with the $i$ th limb can be derived as

$$
q_{i}=\left(\boldsymbol{t}_{1}+(-1)^{i}\left(l_{i 3}+\frac{\boldsymbol{\gamma}-\boldsymbol{\theta}_{i 2}}{2 \pi} p_{i 3}\right)\right) \boldsymbol{w}
$$

Based on Eq. (3), the rotational angles of four motors $\psi$ of two C-drivers are derived as

$$
\boldsymbol{\psi}={ }^{\psi} \mathbf{J}_{X} \boldsymbol{X}
$$

with

$$
\boldsymbol{\psi}=\left[\begin{array}{l}
\psi_{11} \\
\psi_{12} \\
\psi_{21} \\
\psi_{22}
\end{array}\right],{ }^{\psi} \mathbf{J}_{X}=\frac{1}{k}\left[\begin{array}{cccc}
1 & 2 \pi / p_{1} & 0 & 0 \\
1 & 2 \pi / p_{2} & 0 & 0 \\
0 & 0 & 1 & 2 \pi / p_{1} \\
0 & 0 & 1 & 2 \pi / p_{2}
\end{array}\right], \boldsymbol{X}=\left[\begin{array}{c}
\theta_{11} \\
q_{1} \\
\theta_{21} \\
q_{2}
\end{array}\right]
$$

where $\boldsymbol{X}$ represents the outputs of two C-drivers.

\subsection{Velocity analysis}

Taking the derivative of Eqs. (8) and (9) with respect to time, respectively, the velocity of the reference point $\mathrm{P}$ of the output link can be deduced as

$$
\begin{gathered}
l_{i 1}\left(\boldsymbol{\omega}_{i 1} \times \boldsymbol{a}_{i}\right)+l_{i 2}\left(\boldsymbol{\omega}_{i 2} \times \boldsymbol{b}_{i}\right)=\dot{\boldsymbol{t}}_{2} \\
\dot{q}_{i} \boldsymbol{w}=\dot{\boldsymbol{t}}_{1}+(-1)^{i} \frac{\dot{\boldsymbol{\gamma}}-\dot{\boldsymbol{\theta}}_{i 2}}{2 \pi} p_{i 3}
\end{gathered}
$$

where $\boldsymbol{\omega}_{i 1}=\dot{\theta}_{i 1} \boldsymbol{w}$ and $\boldsymbol{\omega}_{i 2}=\dot{\theta}_{i 2} \boldsymbol{w}$ are the angular velocity of links $\mathrm{A}_{i} \mathrm{~B}_{i}$ and $\mathrm{B}_{i} \mathrm{C}_{i}$. Taking the dot product on both sides of Eq. (18) with vector $\boldsymbol{b}_{i}$, the velocity mapping relations are derived as

$$
\dot{\theta}_{i 1}=\frac{-\boldsymbol{b}_{i} \cdot \dot{\boldsymbol{t}}_{2}}{l_{i 1}\left(\boldsymbol{w} \times \boldsymbol{a}_{i}\right) \cdot \boldsymbol{b}_{i}}=\mathbf{J}_{\theta i}^{t} \dot{\boldsymbol{t}}=\mathbf{J}_{\theta i} \dot{\boldsymbol{P}}
$$

with

$$
\mathbf{J}_{\theta i}^{t}=\left[\frac{-\boldsymbol{b}_{i}}{l_{i 1}\left(\boldsymbol{w} \times \boldsymbol{a}_{i}\right) \cdot \boldsymbol{b}_{i}}\right], \mathbf{J}_{\theta i}=\left[\mathbf{J}_{\theta i}^{t} 0\right]
$$

By taking cross product at both sides of Eq. (18) with $\boldsymbol{b}_{i}$, the angular velocity of the passive link $\mathrm{B}_{i} \mathrm{C}_{i}$ can be derived as

$$
\begin{aligned}
\boldsymbol{\omega}_{i 2} & =\left[\dot{\boldsymbol{t}}_{2}-l_{i 1}\left(\boldsymbol{\omega}_{i 1} \times \boldsymbol{a}_{i}\right)\right] \times \boldsymbol{b}_{i} / l_{i 2} \\
& =\left[\boldsymbol{b}_{i} \times\right]\left[\dot{\boldsymbol{t}}_{2}-l_{i 1} \mathbf{J}_{\theta i}^{t} \dot{\boldsymbol{t}}_{2}\left(\boldsymbol{w} \times \boldsymbol{a}_{i}\right)\right] / l_{i 2}=\mathbf{J}_{\boldsymbol{\omega}_{i 2}}^{\boldsymbol{t}} \dot{\boldsymbol{t}}_{2}=\mathbf{J}_{\boldsymbol{\omega}_{i 2}} \dot{\boldsymbol{P}}
\end{aligned}
$$

with 


$$
\begin{aligned}
& \mathbf{J}_{\boldsymbol{\omega}_{i 2}}^{\boldsymbol{t}}=\left(\left[\boldsymbol{b}_{i} \times\right]+l_{i 1}\left[\boldsymbol{b}_{i} \times\right]\left[\left(\boldsymbol{w} \times \boldsymbol{a}_{i}\right) \otimes \mathbf{J}_{\theta i}^{t}\right]\right) / l_{i 2}, \mathbf{J}_{\boldsymbol{\omega}_{i 2}}=\left[\mathbf{J}_{\boldsymbol{\omega}_{i 2}}^{\boldsymbol{t}} \mathbf{I}_{2} \quad \mathbf{0}\right]_{3 \times 4} \\
& {\left[\boldsymbol{b}_{i} \times\right]=\left[\begin{array}{ccc}
0 & b_{i z} & -b_{i y} \\
-b_{i z} & 0 & b_{i x} \\
b_{i y} & -b_{i x} & 0
\end{array}\right]=\left[\begin{array}{ccc}
0 & 0 & -\mathrm{c} \theta_{i 2} \\
0 & 0 & \mathrm{~s} \theta_{i 2} \\
\mathrm{c} \theta_{i 2} & -\mathrm{s} \theta_{i 2} & 0
\end{array}\right] \text {, }} \\
& \mathbf{I}_{1}=\left[\begin{array}{lll}
0 & 0 & 0 \\
0 & 0 & 0 \\
0 & 0 & 1
\end{array}\right], \mathbf{I}_{2}=\left[\begin{array}{lll}
1 & 0 & 0 \\
0 & 1 & 0 \\
0 & 0 & 0
\end{array}\right]
\end{aligned}
$$

where $\otimes$ represents the tensor product.

Then, the Eq. (19) can be rewritten as

$$
\dot{\boldsymbol{q}}_{i}=\left(\dot{\boldsymbol{t}}_{1}+(-1)^{i} \frac{p_{i 3}}{2 \pi}\left(\dot{\gamma}-\mathbf{J}_{\omega_{i 2}}^{t} \dot{\boldsymbol{t}}_{2}\right)\right)=\mathbf{J}_{q_{i}} \dot{\boldsymbol{P}}
$$

with

$$
\mathbf{J}_{q_{i}}=\left[\left(\mathbf{I}_{1}-(-1)^{i} \frac{p_{i 3}}{2 \pi} \mathbf{J}_{\boldsymbol{\omega}_{i 2}}^{\boldsymbol{t}} \mathbf{I}_{2}\right)(-1)^{i} \frac{p_{i 3}}{2 \pi} \boldsymbol{w}\right]_{3 \times 4}
$$

Then, the mapping relations between the output velocities $\dot{\boldsymbol{X}}$ of two C-drivers and Cartesian velocity $\dot{\boldsymbol{P}}$ of the output link are derived as

$$
\dot{X}={ }^{X} \mathbf{J}_{P} \dot{\boldsymbol{P}}
$$

with

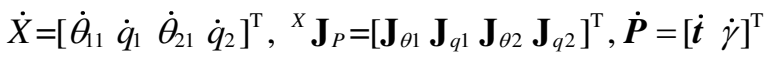

The Jacobian matrix $\boldsymbol{J}$ of the $\underline{\mathrm{C}} \mathrm{R} H-\mathrm{R} R \underline{\mathrm{C}}$ parallel robot transforms the Cartesian velocity $\dot{\boldsymbol{P}}$ of the output link into the motor rates $\dot{\psi}$. The mapping relation between $\dot{\psi}$ and $\dot{\boldsymbol{P}}$ is written as

$$
\dot{\psi}=\mathbf{J} \dot{P}
$$

with

$$
\dot{\boldsymbol{\psi}}=\left[\dot{\psi}_{11}, \dot{\psi}_{12}, \dot{\psi}_{21}, \dot{\psi}_{22}\right]^{\mathrm{T}}, \mathbf{J}={ }^{\psi} \mathbf{J}_{X}{ }^{\mathrm{X}} \mathbf{J}_{P}
$$

Based on above derived angular velocities, the velocities of the mass centers of the links $\mathrm{A}_{i} \mathrm{~B}_{i}$ and $\mathrm{B}_{i} \mathrm{C}_{i}$ are deduced as

$$
\left\{\begin{aligned}
\boldsymbol{v}_{i 1} & =l_{i 1}{ }^{\prime} \boldsymbol{\omega}_{i 1} \times \boldsymbol{a}_{i}=l_{i 1}{ }^{\prime}\left(\boldsymbol{w} \times \boldsymbol{a}_{i}\right) \mathbf{J}_{\theta i}^{t} \dot{\boldsymbol{t}}_{2}=\mathbf{J}_{\mathrm{A} i}^{t} \dot{\boldsymbol{t}}_{2}=\mathbf{J}_{\mathrm{A} i} \dot{\boldsymbol{P}} \\
\boldsymbol{v}_{i 2} & =l_{i 1} \boldsymbol{\omega}_{i 1} \times \boldsymbol{a}_{i}+l_{i 2}{ }^{\prime} \boldsymbol{\omega}_{i 2} \times \boldsymbol{b}_{i} \\
& =\frac{l_{i 1}}{l_{i 1}{ }^{\prime}} \mathbf{J}_{\mathrm{A} i}^{t} \dot{\boldsymbol{t}}_{2}+l_{i 2}{ }^{\prime}\left[\boldsymbol{b}_{i} \times\right] \mathbf{J}_{\boldsymbol{\omega}_{i 2}}^{t_{i}} \dot{\boldsymbol{t}}_{2} \\
& =\mathbf{J}_{\mathrm{B} i}^{t} \dot{\boldsymbol{t}}_{2}=\mathbf{J}_{\mathrm{B} i} \dot{\boldsymbol{P}}
\end{aligned}\right.
$$

where

$$
\left\{\begin{array}{l}
\mathbf{J}_{\mathrm{A} i}^{t}=l_{i 1}{ }^{\prime}\left(\boldsymbol{w} \times \boldsymbol{a}_{i}\right) \otimes \mathbf{J}_{\theta i}^{t}, \mathbf{J}_{\mathrm{A} i}=\left[\begin{array}{ll}
\mathbf{J}_{\mathrm{A} i}^{t} & \mathbf{0}
\end{array}\right]_{3 \times 4} \\
\mathbf{J}_{\mathrm{B} i}^{t}=\frac{l_{i 1}}{l_{i 1}{ }^{\prime}} \mathbf{J}_{\mathrm{A} i}^{t}+l_{i 2}{ }^{\prime}\left[\boldsymbol{b}_{i} \times\right] \mathbf{J}_{\boldsymbol{\omega}_{i 2}}^{t}, \mathbf{J}_{\mathrm{B} i}=\left[\begin{array}{ll}
\mathbf{J}_{\mathrm{B} i}^{t} \mathbf{I}_{2} & \mathbf{0}
\end{array}\right]_{3 \times 4}
\end{array}\right.
$$

where $l_{i 1}{ }^{\prime}$ and $l_{i 2}{ }^{\prime}$ represent the positions of the mass centers of the links $\mathrm{A}_{i} \mathrm{~B}_{i}$ and $\mathrm{B}_{i} \mathrm{C}_{i}$, respectively.

\subsection{Acceleration analysis}

Taking the derivative of Eqs. (18) and (19) with respect to time, respectively, the acceleration mapping functions of the reference point $\mathrm{P}$ of the output link can be deduced as

$$
\begin{gathered}
l_{i 1}\left[\left(\boldsymbol{\varepsilon}_{i 1} \times \boldsymbol{a}_{i}\right)+\boldsymbol{\omega}_{i 1} \times\left(\boldsymbol{\omega}_{i 1} \times \boldsymbol{a}_{i}\right)\right]+l_{i 2}\left[\varepsilon_{i 2} \times \boldsymbol{b}_{i}+\boldsymbol{\omega}_{i 2} \times\left(\boldsymbol{\omega}_{i 2} \times \boldsymbol{b}_{i}\right)\right]=\ddot{\boldsymbol{t}}_{2} \\
\ddot{q}_{i} \boldsymbol{w}=\ddot{\boldsymbol{t}}_{1}+(-1)^{i} \frac{p_{i 3}}{2 \pi}\left(\ddot{\gamma}-\boldsymbol{\varepsilon}_{i 2}\right)
\end{gathered}
$$

where $\varepsilon_{i 1}=\ddot{\theta}_{i 1} \boldsymbol{w}$ and $\varepsilon_{i 2}$ are the angular accelerations of links $\mathrm{A}_{i} \mathrm{~B}_{i}$ and $\mathrm{B}_{i} \mathrm{C}_{i}$, respectively. Taking the dot product on both sides of Eq. (26) with vector $\boldsymbol{b}_{i}$, the acceleration mapping relations are derived as

$$
\ddot{\theta}_{i 1}=\frac{-\boldsymbol{b}_{i} \cdot \ddot{\boldsymbol{t}}_{2}}{l_{i 1}\left(\boldsymbol{w} \times \boldsymbol{a}_{i}\right) \cdot \boldsymbol{b}_{i}}-\frac{l_{i 1} \dot{\theta}_{i 1}{ }^{2} \boldsymbol{a}_{i} \cdot \boldsymbol{b}_{i}+l_{i 2} \boldsymbol{\omega}_{i 2}^{2}}{l_{i 1}\left(\boldsymbol{w} \times \boldsymbol{a}_{i}\right) \cdot \boldsymbol{b}_{i}}=\mathbf{J}_{\theta i} \ddot{\boldsymbol{P}}+\ddot{\theta}_{i 1}{ }^{\prime}
$$

where

$$
\ddot{\theta}_{i 1}{ }^{\prime}=-\frac{l_{i 1} \dot{\theta}_{i 1}{ }^{2} \boldsymbol{a}_{i} \cdot \boldsymbol{b}_{i}+l_{i 2} \boldsymbol{\omega}_{i 2}{ }^{2}}{l_{i 1}\left(\boldsymbol{w} \times \boldsymbol{a}_{i}\right) \cdot \boldsymbol{b}_{i}}
$$

By taking cross product at both sides of Eq. (26) with $\boldsymbol{b}_{i}$, the angular acceleration of the passive link $\mathrm{B}_{i} \mathrm{C}_{i}$ can be derived as

$$
\boldsymbol{\varepsilon}_{i 2}=\left[\ddot{\boldsymbol{t}}_{2}+l_{i 1}\left[\ddot{\theta}_{i 1}\left(\boldsymbol{w} \times \boldsymbol{a}_{i}\right)+\dot{\theta}_{i 1}{ }^{2} \boldsymbol{a}_{i}\right]\right] \times \boldsymbol{b}_{i} / l_{i 2}=\mathbf{J}_{\omega_{i 2}}^{\boldsymbol{t}} \ddot{\boldsymbol{t}}_{2}+\boldsymbol{\varepsilon}_{i 2}{ }^{\prime}
$$
with

$$
\left.\boldsymbol{\varepsilon}_{i 2}{ }^{\prime}=\left[\boldsymbol{b}_{i} \times\right]\left[l_{i 1} \ddot{\theta}_{i 1}{ }^{\prime}\left(\boldsymbol{w} \times \boldsymbol{a}_{i}\right)+l_{i 1} \boldsymbol{\omega}_{i 1}{ }^{2} \boldsymbol{a}_{i}\right)\right] / l_{i 2}
$$

Then, the Eq. (27) can be rewritten as

$$
\ddot{\boldsymbol{q}}_{i}=\left(\ddot{\boldsymbol{t}}_{1}+(-1)^{i} \frac{p_{i 3}}{2 \pi}\left(\ddot{\gamma}-\mathbf{J}_{\boldsymbol{\omega}_{i 2}}^{\boldsymbol{t}} \ddot{\boldsymbol{t}}_{2}-\boldsymbol{\varepsilon}_{i 2}{ }^{\prime}\right)\right)=\mathbf{J}_{q_{i}} \ddot{\boldsymbol{P}}+\ddot{\boldsymbol{q}}_{i}{ }^{\prime}
$$

with

$$
\ddot{q}_{i}{ }^{\prime}=-(-1)^{i} \frac{p_{i 3}}{2 \pi} \varepsilon_{i 2}{ }^{\prime}
$$

Based on Eq. (24), the mapping relation between $\ddot{\psi}$ and $\ddot{\boldsymbol{X}}$ is written as

$$
\ddot{\boldsymbol{\psi}}={ }^{\psi} \mathbf{J}_{X} \ddot{\boldsymbol{X}}
$$

with

$$
\ddot{\psi}=\left[\ddot{\psi}_{11}, \ddot{\psi}_{12}, \ddot{\psi}_{21}, \ddot{\psi}_{22}\right]^{\mathrm{T}}, \ddot{\boldsymbol{X}}=\left[\ddot{\theta}_{11}, \ddot{q}_{1}, \ddot{\theta}_{21}, \ddot{q}_{2}\right]^{\mathrm{T}}
$$

Then, the accelerations of the mass centers of the links $\mathrm{A}_{i} \mathrm{~B}_{i}$ and $\mathrm{B}_{i} \mathrm{C}_{i}$ are deduced as

$$
\left\{\begin{aligned}
\boldsymbol{a}_{i 1} & =l_{i 1}{ }^{\prime}\left[\ddot{\theta}_{i 1} \boldsymbol{w} \times \boldsymbol{a}_{i}-\dot{\theta}_{i 1}{ }^{2} \boldsymbol{a}_{i}\right]=\mathbf{J}_{\mathrm{A} i} \ddot{\boldsymbol{P}}+\boldsymbol{a}_{i 1}{ }^{\prime} \\
\boldsymbol{a}_{i 2} & =l_{i 1}\left[\ddot{\theta}_{i 1} \boldsymbol{w} \times \boldsymbol{a}_{i}-\dot{\theta}_{i 1}{ }^{2} \boldsymbol{a}_{i}\right]+l_{i 2}{ }^{\prime}\left[\boldsymbol{\varepsilon}_{i 2} \times \boldsymbol{b}_{i}-\boldsymbol{\omega}_{i 2}{ }^{2} \boldsymbol{b}_{i}\right] \\
& =\mathbf{J}_{\mathrm{B} i} \ddot{\boldsymbol{P}}+\boldsymbol{a}_{i 2}{ }^{\prime}
\end{aligned}\right.
$$

where

$$
\left\{\begin{array}{l}
\boldsymbol{a}_{i 1}{ }^{\prime}=l_{i 1}{ }^{\prime}\left(\ddot{\theta}_{i 1}{ }^{\prime} \boldsymbol{w} \times \boldsymbol{a}_{i}-\dot{\theta}_{i 1}{ }^{2} \boldsymbol{a}_{i}\right) \\
\boldsymbol{a}_{i 2}{ }^{\prime}=l_{i 1}\left(\ddot{\theta}_{i 1}{ }^{\prime} \boldsymbol{w} \times \boldsymbol{a}_{i}-\dot{\theta}_{i 1}{ }^{2} \boldsymbol{a}_{i}\right)+l_{i 2}{ }^{\prime}\left(\left[\boldsymbol{b}_{i} \times\right] \boldsymbol{\varepsilon}_{i 2}{ }^{\prime}-\boldsymbol{\omega}_{i 2}{ }^{2} \boldsymbol{b}_{i}\right)
\end{array}\right.
$$

\section{Workspace and singularity analysis}

\subsection{Workspace}

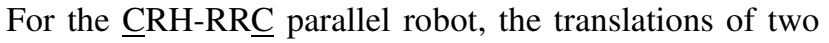
limbs determine the translation and full cycle rotation of the output link along $\boldsymbol{w}$-direction. And the output link can 
fully circle rotate along $\boldsymbol{w}$-direction at any position in reachable workspace. All operation tasks are executed in reachable workspace. Therefore, the workspace of the mechanism is a key important concept that reflects their performances. In this paper, the structural parameters of the $\underline{C R H-R R C}$ parallel robot are presented in Appendix. Besides, the ranges of the outputs of the $\mathrm{C}$-driver and angles of passive joints determine the volume of the workspace. The ranges of the outputs of the C-driver are given as $0 \mathrm{~mm}<q_{i}<500 \mathrm{~mm},-80^{\circ}<\theta_{11}<100^{\circ}$ and $-100^{\circ}<\theta_{21}<80^{\circ}$. From the point of view of structural design, the angles of passive joints are given as $-170^{\circ}<\theta_{i 2}<170^{\circ}$. Then, the position workspace of the $\underline{\mathrm{C}} \mathrm{RH}-\mathrm{RR} \underline{\mathrm{C}}$ parallel robot is obtained based on the above position analysis, as drawn in Figure 3. The position workspace is a three-dimensional volume formed by the section (Figure 3(b)) translating along the $Z$-axis.

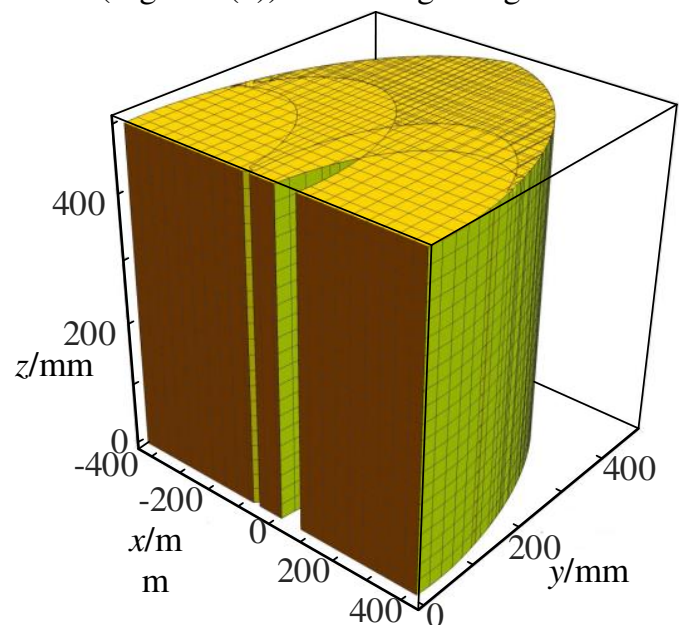

(a)

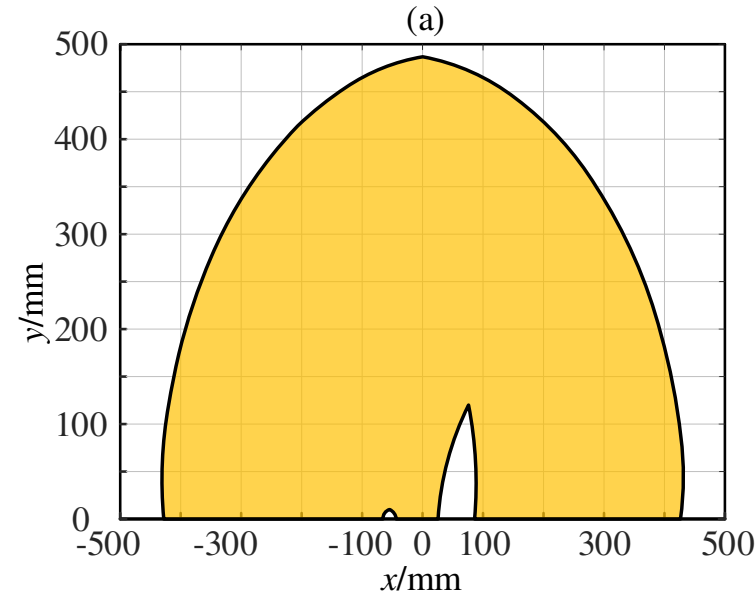

(b)

Figure 3 Workspace of $\underline{C R H-R R C}$ parallel robot: (a) three-dimensional volume; (b) section on the plane $(\mathrm{z}=200 \mathrm{~mm})$

\subsection{Singularity}

Singularities is an inherent property of parallel robot. The mechanism will lose or increase DOFs at singular configurations. Under singular configurations, the parallel robot cannot operate stably, and the kinematic performance will thus deteriorate, even damage to mechanism.

For a $\underline{C R H-R R} \underline{\mathrm{C}}$ parallel robot, when the translations of two C-drivers are locked, CRH-RRC parallel robot will degenerate to $\underline{R} R-R R \underline{R}$ plan 2-DOF single-loop parallel mechanism. Obviously, singularity analysis of the $\underline{C} R H-R R \underline{C}$ parallel robot can switch into singularity analysis of the $\underline{R} R-R R \underline{R}$ plan mechanism, which reduce a lot of workloads. When the Jacobian matrix becomes rank-deficient, the mechanism will locate at a singularity configuration. According to Eq. (20), the Jacobin matrix of the $\underline{R} R-R R \underline{R}$ plan mechanism can be derived as

$$
\mathbf{J}_{\theta} \dot{\boldsymbol{\theta}}=\mathbf{J}_{P} \dot{\boldsymbol{t}}^{\prime}
$$

with

$$
\begin{aligned}
& \dot{\boldsymbol{\theta}}=\left[\dot{\theta}_{11}, \dot{\theta}_{21}\right]^{\mathrm{T}}, \dot{\boldsymbol{t}}^{\prime}=[\dot{x}, \dot{y}]^{\mathrm{T}}, \\
& \mathbf{J}_{\theta}=\left[\begin{array}{cc}
l_{11}\left(\boldsymbol{w} \times \boldsymbol{a}_{1}\right) \cdot \boldsymbol{b}_{1} & 0 \\
0 & l_{21}\left(\boldsymbol{w} \times \boldsymbol{a}_{2}\right) \cdot \boldsymbol{b}_{2}
\end{array}\right], \mathbf{J}_{\mathrm{P}}=\left[\begin{array}{ll}
\boldsymbol{b}_{1} \cdot \boldsymbol{u} & \boldsymbol{b}_{1} \cdot \boldsymbol{v} \\
\boldsymbol{b}_{2} \cdot \boldsymbol{u} & \boldsymbol{b}_{2} \cdot \boldsymbol{v}
\end{array}\right]
\end{aligned}
$$

According to the singularity analysis in literature [43], the singularity can be divided into three types: Type-I, direct-kinematics singularity; Type-II, inverse-kinematics singularity; and Type-III, combined singularity. Besides, the constraint-singularities [44] are also considered, which cannot be identified by the rank-deficiency of the Jacobian matrices.

\subsubsection{Type-I: Direct-kinematics singularity}

Type-I singularity occurs when the $\mathbf{J}_{\mathrm{P}}$ matrix is rank-deficient, in other word, the determinant of the $\mathbf{J}_{\mathbf{P}}$ vanishes. Based on Eq. (33b), the singularity condition can thus be derived as

$$
\boldsymbol{b}_{1} \cdot \boldsymbol{b}_{2}= \pm 1
$$

In this case, the link $\mathrm{B}_{1} \mathrm{C}_{1}$ and $\mathrm{B}_{2} \mathrm{C}_{2}$ are collinear, as shown in Figure 4 (a) and (b).

\subsubsection{Type-II: Inverse-kinematics singularity}

The mechanism locates at an inverse-kinematics singularity when $\mathbf{J}_{\theta}$ becomes rank-deficient. The determinant of the diagonal matrix $\mathbf{J}_{\theta}$ is equal to zero, namely, at least one of its diagonal elements are zero, the singularity conditions can thus be derived as

$$
\left\{\begin{array}{l}
\boldsymbol{a}_{1} \cdot \boldsymbol{b}_{1}=1 \\
\boldsymbol{a}_{2} \cdot \boldsymbol{b}_{2}=1 \\
\boldsymbol{a}_{1} \cdot \boldsymbol{b}_{1}=1, \boldsymbol{a}_{2} \cdot \boldsymbol{b}_{2}=1
\end{array}\right.
$$

Here, considering the inference between links, these conditions, i.e., $\boldsymbol{a}_{i} \cdot \boldsymbol{b}_{i}=-1$, do not exist. In this case, the link $\mathrm{A}_{1} \mathrm{~B}_{1}$ and $\mathrm{B}_{1} \mathrm{C}_{1}$ are collinear, or the link $\mathrm{A}_{2} \mathrm{~B}_{2}$ and $\mathrm{B}_{2} \mathrm{C}_{2}$ are collinear, or both conditions hold at the same time, as 
(a)

(c)

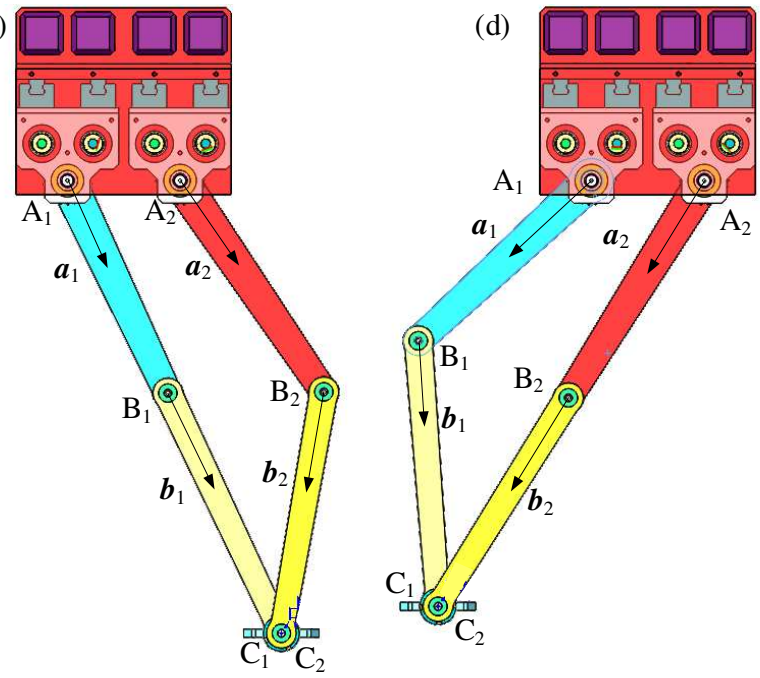

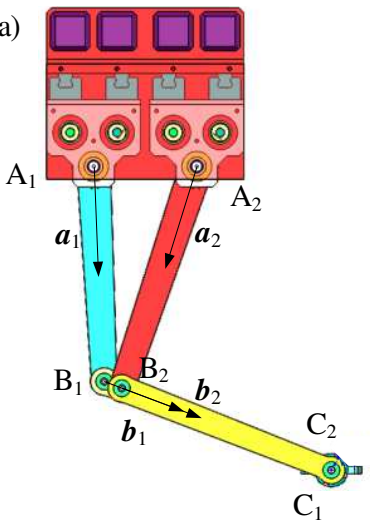

(d) (e)
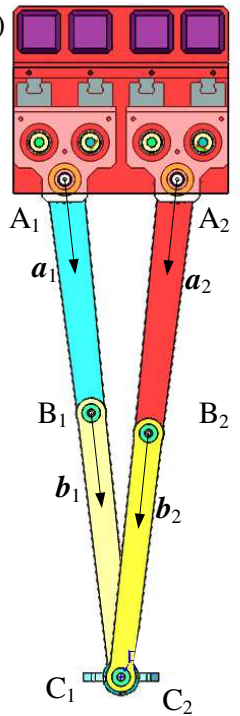

(b)

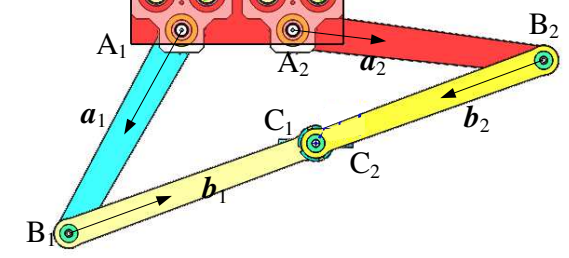

(f)

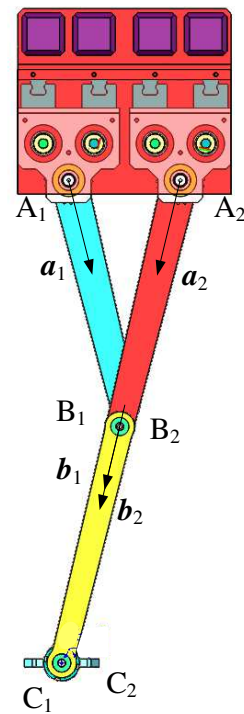

(g)

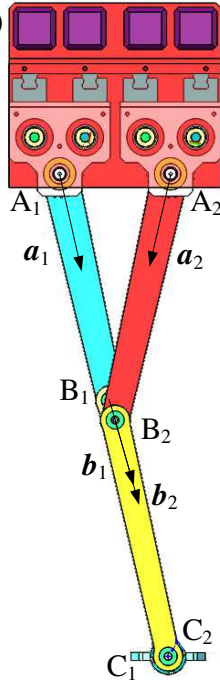

Figure 4 Singularity configurations: (a) (b) Type-I; (c) (e) Type-II; (f) (g) Type-III.

shown in Figure 4 (c-e).

\subsubsection{Type-III: Combined singularity}

The combined singularity occurs when both $\mathbf{J}_{\mathrm{P}}$ and $\mathbf{J}_{\theta}$ are rank-deficient simultaneously. Hence, when both the singularity conditions of Type-I and Type-II hold simultaneously, the mechanism finds itself at a combined singularity. The singularity configurations are shown in Figure 4 (f) and (g).

\subsubsection{Constraint-Singularity}

According to the mobility analysis, since the axis-directions of all joints of two limbs are constant, i.e., along the $\boldsymbol{w}$-direction, hence, the constraints of two limbs are constant, the constraints exacted on the output link do not change. This type of singularity, therefore, will never occur in the mechanism.

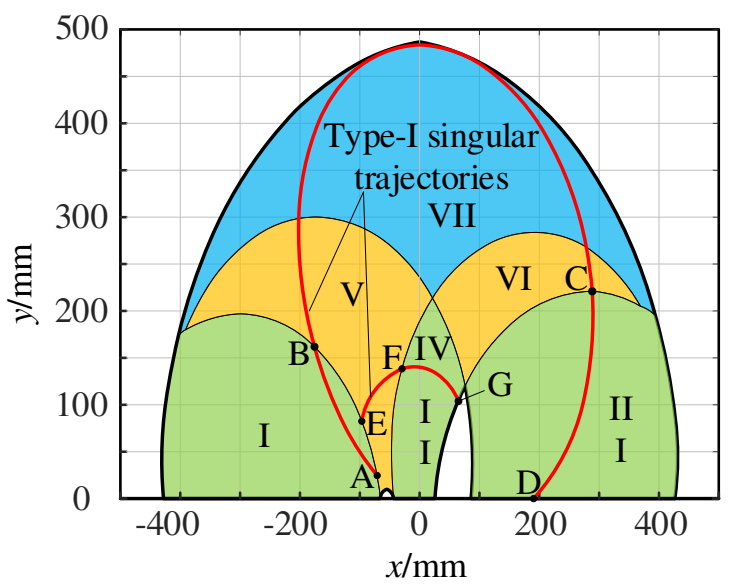

Figure 5 Singularity trajectories

Obviously, type-I singularity appears in the internal of the workspace, and type-II singularity occurs at the boundary of the workspace. In engineering application, the output link only moves in the internal workspace, and 
hardly arrives the boundary of the workspace. Hence, type-I singularity is the focus of study, especially, for trajectory planning. Type-I singularity trajectories on the plane $(\mathrm{z}=200 \mathrm{~mm})$ are drawn in Figure 5 based on Eq. (34).

\subsubsection{Singularity avoidance}

When planning trajectory to execute the operation task, the singularity must be avoided to prevent loss of control or damage to the machine. Base on Eq. (12), when giving a position of the output link, the outputs $\theta_{i 1}$ of two $\mathrm{C}$-drivers have two solutions, respectively, which means that the singularity can be avoided by selecting suitable solutions. Based on the above singularity analysis, the reachable workspace can be divided into seven blocks, i.e., I VII, as shown in Figure 5. Due to the limitations of the $\theta_{i 1}(i=1,2)$ of the two C-drivers, when the reference point $\mathrm{P}$ of the output link locates in block-I IV, there is only one set of corresponding solutions of $\theta_{i 1}$; when the reference point $\mathrm{P}$ of the output link locates in block-V VI, there are two sets of corresponding solutions of $\theta_{i 1}$; when the reference point $\mathrm{P}$ of the output link locates in block-VII, there are four sets of corresponding solutions of $\theta_{i 1}$. Hence, when the output link passes the curve-AB, curve-CD and curve-FG, the parallel manipulator must locate at singularity configuration, and the output link of parallel manipulator loss of control, the moving direction of the output link will not be determined by two C-drivers. Hence, when planning trajectory, we should avoid the output link passing through singularity trajectory curve-AB, curve-CD and curve-FG. For the position points of curve-BC and curve-EF, there are at least two sets of corresponding solutions of $\theta_{i 1}$ however, only one set of solution of $\theta_{i 1}$ will make the parallel manipulator, other solutions will not, hence, the output can directly pass-through curve-BC and curve-EF by selecting a set of suitable solution of $\theta_{i 1}$.

\section{Dynamics}

To derive the inverse dynamic model of the proposed Schönflies motion parallel robot using the principle of virtual work method, it is assumed that the frictional forces and torques are negligible, and the only change in virtual work is associated with the external wrenches exerted to the robot. After, applied and inertia force system exerted to each component is discussed in what follows.

For the output link, applied and inertia force system exerted at its center of mass are derived as

$$
\mathbf{F}_{\mathrm{o}}=\left[\begin{array}{c}
\mathbf{f}_{\mathrm{E}}+\mathrm{m}_{\mathrm{o}}(\mathbf{g}-\ddot{\boldsymbol{t}}) \\
\boldsymbol{\tau}_{\mathrm{E}}-{ }^{G} \mathbf{I}_{\mathrm{o}} \ddot{\boldsymbol{\gamma}}-\dot{\boldsymbol{\gamma}} \times\left({ }^{G} \mathbf{I}_{\mathrm{o}} \dot{\boldsymbol{\gamma}}\right)
\end{array}\right]
$$

with

$$
{ }^{G} \mathrm{I}_{\mathrm{o}}={ }^{G} \mathbf{R}_{\mathrm{o}} \mathbf{I}_{\mathrm{o}}{ }^{G} \mathbf{R}_{\mathrm{o}}^{\mathrm{T}}
$$

therein $f_{\mathrm{E}}$ and $\tau_{\mathrm{E}}$ represent the external force and torque exerted at the center of mass of the output link; $\mathrm{m}_{\mathrm{o}}$ is the mass of the output link while $\mathbf{g}$ is the gravity acceleration vector. $\dot{\gamma}=\dot{\gamma} \boldsymbol{w}$ and $\ddot{\gamma}=\ddot{\gamma} \boldsymbol{w}$ are the output link angular velocity and acceleration, respectively. $\mathbf{I}_{\mathrm{o}}$ is the inertia matrix of the output link described in the output link frame $\{\boldsymbol{O}\}$ about the mass center while ${ }^{G} \mathrm{R}_{\mathrm{o}}$ is the rotation matrix between the output link frame $\{\boldsymbol{O}\}$ and fixed frame $\{\boldsymbol{G}\}$.

For the link of the proposed Schönflies motion parallel robot, assuming that gravitational force is the only external force. Let $\mathrm{m}_{\mathrm{L} i j}$ be a mass of the $j$ th link associated with the $i$ th limb. Then, the force system exerted at the mass center of the $j$ th link associated with the $i$ th limb can be derived in the fixed frame $\{\boldsymbol{G}\}$ as

$$
\mathbf{F}_{\mathrm{L}_{i j}}=\left[\begin{array}{c}
\mathrm{m}_{\mathrm{L} i j}\left(\mathbf{g}-\left(\boldsymbol{a}_{\mathrm{L} i j}+\ddot{\boldsymbol{q}}_{i}\right)\right) \\
-{ }^{G} \mathbf{I}_{\mathrm{L}_{i j}} \boldsymbol{\varepsilon}_{i j}-\boldsymbol{\omega}_{i j} \times\left({ }^{G} \mathbf{I}_{\mathrm{L} i j} \boldsymbol{\omega}_{i j}\right)
\end{array}\right]
$$

with

$$
{ }^{G} \mathbf{I}_{\mathrm{L}_{i j}}={ }^{G} \mathbf{R}_{\mathrm{L}_{i j}} \mathbf{I}_{\mathrm{L}_{i j}}{ }^{G} \mathbf{R}_{\mathrm{L}_{i j}}^{\mathrm{T}}
$$

where $\mathbf{I}_{L_{i j}}$ is the inertia matrix of the $j$ th link associated with the $i$ th limb described in the link frame $\left\{\boldsymbol{L}_{i j}\right\}$ about the mass center while ${ }^{G} \mathrm{R}_{\mathrm{L}_{i j}}$ is the rotation matrix between the link frame $\left\{\boldsymbol{L}_{i j}\right\}$ and fixed frame $\{\boldsymbol{G}\}$. In same below.

For the C-driver, the force system exerted at the mass center of each moving part associated with $\mathrm{C}$-driver can be deduced the fixed frame $\{\boldsymbol{G}\}$ as

$$
\left\{\begin{aligned}
\mathbf{F}_{\mathrm{N} i j} & =\left[\begin{array}{c}
\mathrm{m}_{\mathrm{N} i j}\left(\mathbf{g}-\ddot{\boldsymbol{q}}_{i}\right) \\
-{ }^{G} \mathbf{I}_{\mathrm{N} i j} \boldsymbol{\varepsilon}_{i 1}-\boldsymbol{\omega}_{i 1} \times\left({ }^{G} \mathbf{I}_{\mathrm{N} i j} \boldsymbol{\omega}_{i 1}\right)
\end{array}\right] \\
\mathbf{F}_{\mathrm{S} i j} & =\left[\begin{array}{c}
\mathbf{0} \\
-{ }^{G} \mathbf{I}_{\mathrm{S} i j} \ddot{\boldsymbol{\psi}}_{i j}-\dot{\boldsymbol{\psi}}_{i j} \times\left({ }^{G} \mathbf{I}_{\mathrm{S} i j} \dot{\boldsymbol{i}}_{i j}\right)
\end{array}\right] \\
\mathbf{F}_{\mathrm{B} i} & =\left[\begin{array}{c}
\mathrm{m}_{\mathrm{B} i}\left(\mathbf{g}-\ddot{\boldsymbol{q}}_{i}\right) \\
\mathbf{0}
\end{array}\right]
\end{aligned}\right.
$$

Subscripts N, S and B represent the nut, screw and bracket, respectively, as shown in Figure 1(b). For example, symbol $\mathbf{F}_{S i j}$ indicated the force system exerted at the mass center of the $j$ th screw of C-driver associated with the $i$ th limb.

Now, the dynamic equation can be obtained according to the principle of virtual work as

$$
\begin{aligned}
\sum_{i=1}^{2} \sum_{j=1}^{2}\left(\delta \boldsymbol{X}_{\mathrm{S} i j}^{\mathrm{T}} \mathbf{F}_{\mathrm{S} i j}+\delta \boldsymbol{X}_{\mathrm{N} i j}^{\mathrm{T}} \mathbf{F}_{\mathrm{N} i j}+\delta \boldsymbol{X}_{\mathrm{L} i j} \mathbf{F}_{\mathrm{L} i j}\right) \\
+\sum_{i=1}^{2} \delta \boldsymbol{X}_{\mathrm{Bi}}^{\mathrm{T}} \mathbf{F}_{\mathrm{B} i}+\delta \boldsymbol{\psi}^{\mathrm{T}} \boldsymbol{\tau}+\delta \boldsymbol{P}^{\mathrm{T}} \mathbf{F}_{\mathrm{o}}=0
\end{aligned}
$$


where $\delta \boldsymbol{X}_{\mathrm{S} i j}, \delta \boldsymbol{X}_{\mathrm{N} i j}, \delta \boldsymbol{X}_{\mathrm{B} i}, \delta \boldsymbol{X}_{\mathrm{L} i j}$ and $\delta \boldsymbol{P}$ are corresponding virtual placements of the moving components expressed in the fixed frame $\{\boldsymbol{G}\}$ in the given order: screw; nut; bracket; link; and output link, respectively. Based on the kinematic analysis in Section 3, virtual placements of the screw, nut, bracket and link can be expressed with the virtual displacement of the output link $\delta \boldsymbol{P}$ as

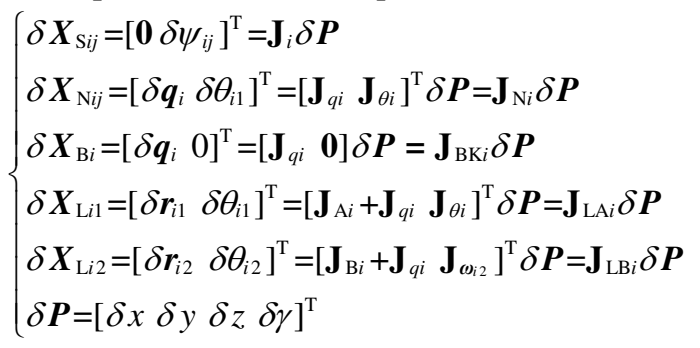

Substituting Eq. (40) into Eq. (39), then, the inverse dynamics of the proposed Schönflies motion parallel robot can be deduced as

$$
\begin{aligned}
\boldsymbol{\tau}= & -\mathbf{J}^{-\mathrm{T}}\left(\sum_{i=1}^{2} \sum_{j=1}^{2}\left(\mathbf{J}_{i}{ }^{\mathrm{T}} \mathbf{F}_{\mathrm{S} i j}+\mathbf{J}_{\mathrm{N} i}{ }^{\mathrm{T}} \mathbf{F}_{\mathrm{N} i j}\right)\right. \\
& \left.+\sum_{i=1}^{2}\left(\mathbf{J}_{\mathrm{LA} i}{ }^{\mathrm{T}} \mathbf{F}_{\mathrm{L} i 1}+\mathbf{J}_{\mathrm{LB} i}{ }^{\mathrm{T}} \mathbf{F}_{\mathrm{L} i 2}+\mathbf{J}_{\mathrm{BK} i}{ }^{\mathrm{T}} \mathbf{F}_{\mathrm{B} i}\right)+\mathbf{F}_{\mathrm{o}}\right)
\end{aligned}
$$

where $\mathbf{J}^{-\mathrm{T}}$ is the inverse matrix of $\mathrm{J}^{\mathrm{T}}$, and $\boldsymbol{\tau}=\left[\tau_{11}, \tau_{12}, \tau_{21}\right.$, $\left.\tau_{22}\right]^{\mathrm{T}}$, they are the driving torques of four motors.

\section{Simulation study}

To display the performances, the kinematic and dynamic performances of the proposed Schönflies motion parallel robot and serial SCRAR robot are compared by implementing identical pick-place task. A target is picked from position $\mathrm{A}$ then placed to position $\mathrm{B}$, during from $\mathrm{A}$ to $\mathrm{B}$, the target rotates angle $\Delta \gamma$ along $w$-direction. The trajectory of the target is shown in Figure 6.

The trajectory is composed of three segments, i.e., T: $\mathrm{T}_{i}\left(x_{i}, y_{i}, z_{i}, \gamma_{i}\right)(i=1,2,3)$, which can be described as

$$
\left\{\begin{array}{l}
x_{i}=\sum_{i=1}^{i} \Delta x_{i-1}+\Delta x_{i}\left[\left(t-\sum_{i=1}^{i} t_{i-1}\right) / t_{i}-\sin \left[2 \pi\left(t-\sum_{i=1}^{i} t_{i-1}\right) / t_{i}\right] /(2 \pi)\right] \\
y_{i}=\sum_{i=1}^{i} \Delta y_{i-1}+\Delta y_{i}\left[\left(t-\sum_{i=1}^{i} t_{i-1}\right) / t_{i}-\sin \left[2 \pi\left(t-\sum_{i=1}^{i} t_{i-1}\right) / t_{i}\right] /(2 \pi)\right] \\
z_{i}=\sum_{i=1}^{i} \Delta z_{i-1}+\Delta z_{i}\left[\left(t-\sum_{i=1}^{i} t_{i-1}\right) / t_{i}-\sin \left[2 \pi\left(t-\sum_{i=1}^{i} t_{i-1}\right) / t_{i}\right] /(2 \pi)\right] \\
\gamma_{i}=\sum_{i=1}^{i} \Delta \gamma_{i-1}+\Delta \gamma_{i}\left[\left(t-\sum_{i=1}^{i} t_{i-1}\right) / t_{i}-\sin \left[2 \pi\left(t-\sum_{i=1}^{i} t_{i-1}\right) / t_{i}\right] /(2 \pi)\right]
\end{array}\right.
$$

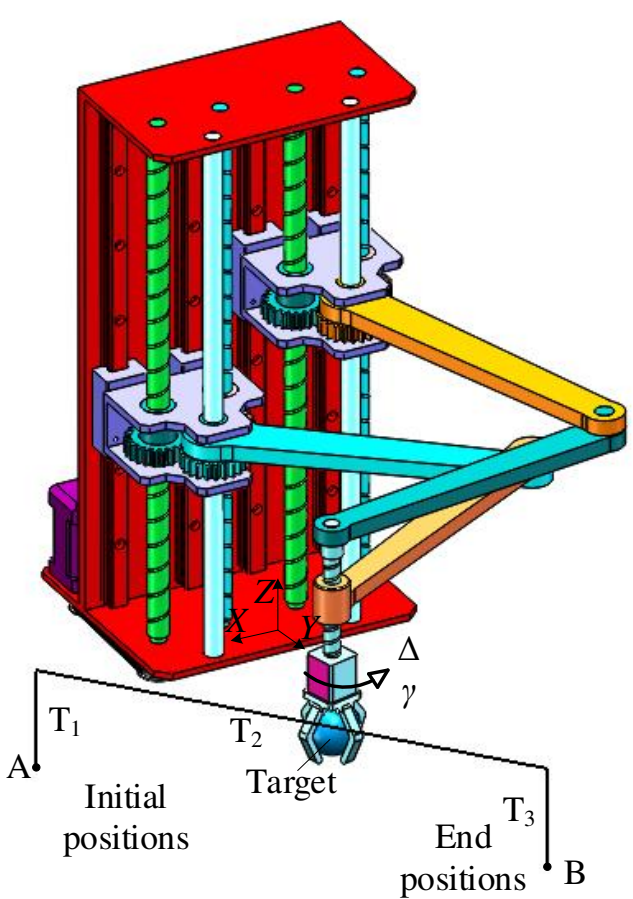

(a)

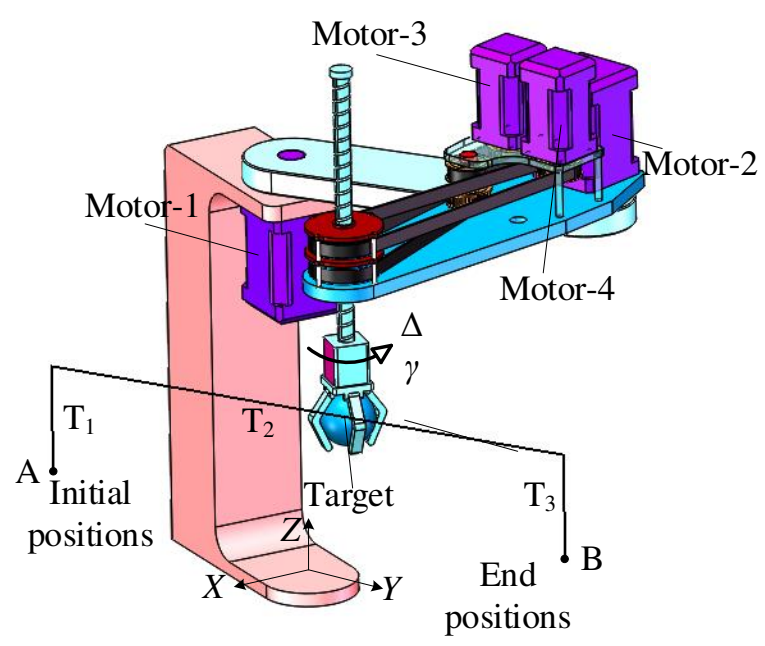

(b)

Figure 6 Trajectory for pick-place task: (a) Schönflies motion parallel robot; (b) serial SCRAR robot

$\left\{\begin{array}{l}\Delta x_{0}=250 \\ \Delta y_{0}=100 \\ \Delta z_{0}=0 \\ \Delta \gamma_{0}=0 \\ t_{0}=0\end{array},\left\{\begin{array}{l}\Delta x_{i}=0,-250,0 \\ \Delta y_{i}=0,300,0 \\ \Delta z_{i}=80,0,-80, i=1,2,3 \\ \Delta \gamma_{i}=0, \pi, 0 \\ t_{i}=1,0.5,1\end{array}\right.\right.$

With 


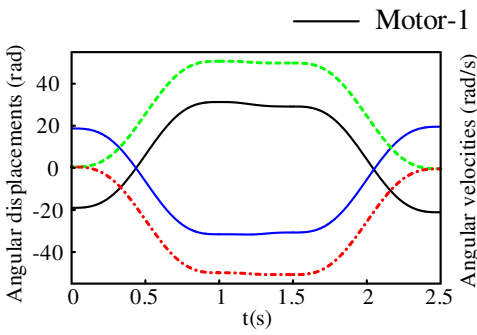

Motor-2 - - Motor-3 - - Motor-4
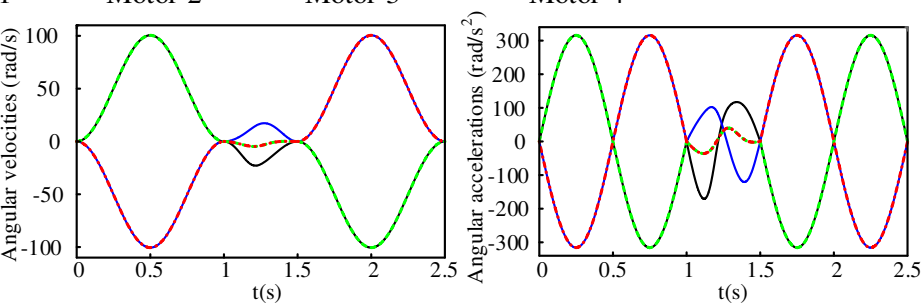

(a)

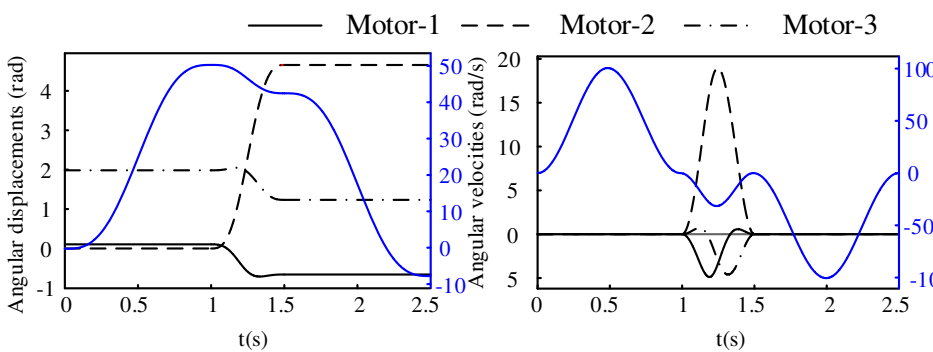

(b)

Figure 7 Displacements, velocities and accelerations of four motors: (a) Schönflies motion parallel robot; (b) serial SCRAR robot. In Figure 7(b), blue curves are corresponded to blue axis ruler.
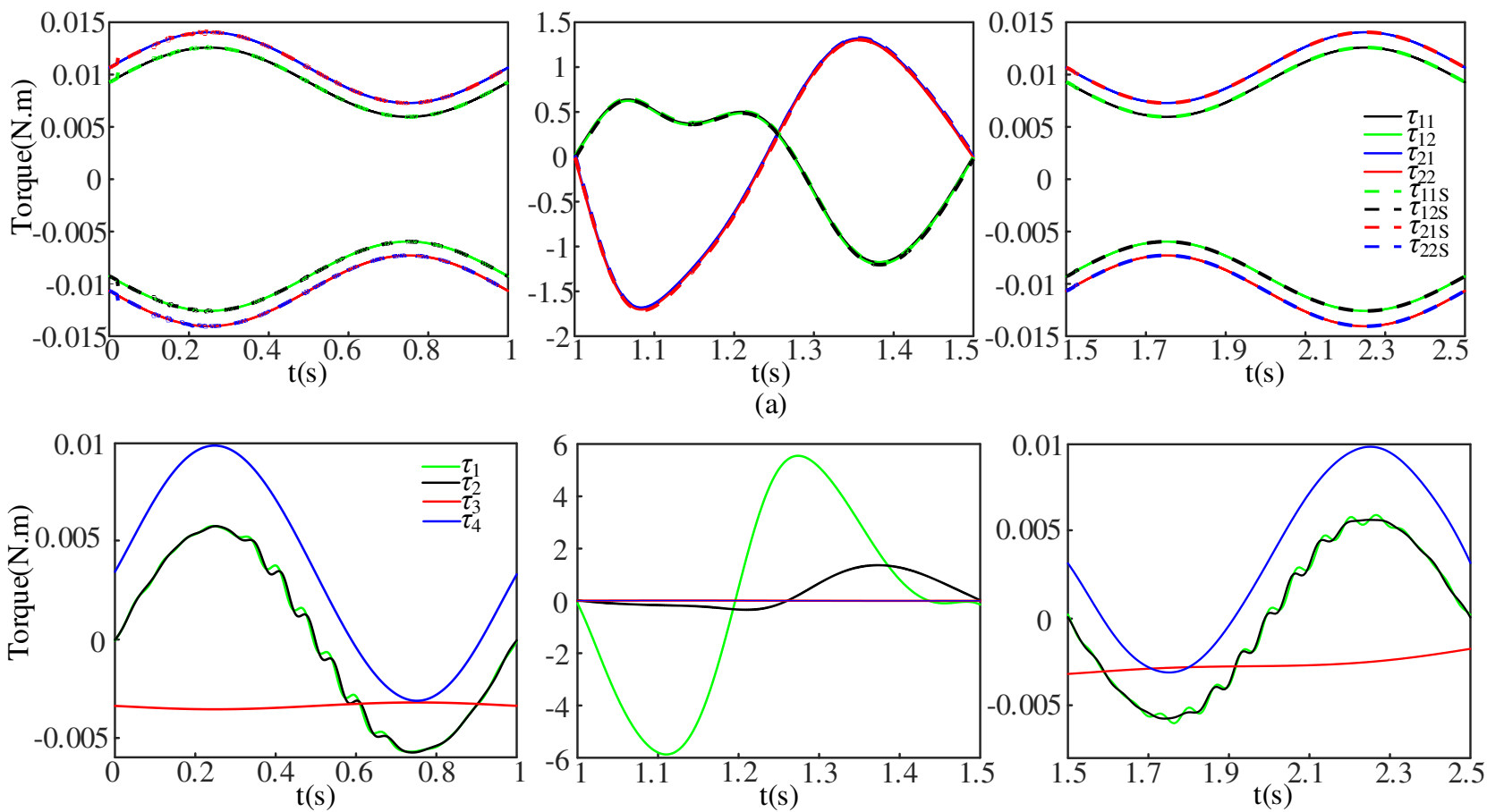

(b)

Figure 8 Driving torques at four motors for the pick-place task: (a) Schönflies motion parallel robot; (b) serial SCRAR robot. In

Figure8 (a), full lines represent the result of theoretical model and dotted lines represent the results of simulation.

The trajectory is planned based on Eq. (42). Then, displacements, velocities, and accelerations of four motors for the given trajectory are obtained based on kinematics analysis in Section 3 and are drawn as shown in Figure 7. For serial SCARA robot, the kinematics analysis is omitted, because it can be obtained easily according to the kinematic analysis in Section 3.

The kinematic and dynamic parameters are listed in 
Appendix, then, the driving torque of each motor of the proposed Schönflies motion parallel robot is obtained by theory derivation and simulation, as shown in Figure 8(a). The driving torque of each motor of serial SCRAR robot is obtained by simulation, as shown in Figure 8(b).

As can be seen from Figure 8, implementing same pick and place task, the maximal torque of the proposed Schönflies motion parallel robot is less than one-third of serial SCRAR robot. Moreover, for the proposed Schönflies motion parallel robot, the driving torques are suitably distributed to four motors, and there is not much difference between the torque of each motor. However, for the serial SCRAR robot, the torque of Motor-1 is very larger than that of other motors, the torque distribution between motors is imbalanced, which causes an excessive load on Motor-1.

\section{Conclusions}

(1) A novel single-loop Schönflies motion parallel robot driven by a C-driver, in which the output link has full circle rotation capability, is designed. Compared with other Schönflies motion robots, this robot uses the least numbers of links and joints to achieve the Schönflies motion. And the structure is very simplified.

(2) The kinematics analysis indicates that the kinematics of novel Schönflies motion parallel robot is simplified, and the workspace is large, the singularity analysis can be switched into that of a $5 \mathrm{R}$ plane linkage mechanism, which is very easy. The singularity can be avoided effectively and quickly.

(3) The dynamic model was built based on the principle of virtual work. A pick-and-place task was implemented, and the simulation results verified the correctness of the theoretical model.

(4) The results of simulation show that proposed single-loop Schönflies motion parallel robot distributes the torque of the motor well, and the maximal torque of the Schönflies motion parallel robot is less than one-third of serial SCRAR robot. Under the identical condition of motor parameters, the single-loop Schönflies motion parallel robot can complete the task of the higher requirements.

\section{Declaration}

\section{Acknowledgements}

The authors sincerely thanks to Professor Yuefa Fang of Beijing Jiaotong University for his critical discussion and reading during manuscript preparation.

\section{Funding}

Supported by National Natural Science Foundation of China under grant no. 51975039.

\section{Availability of data and materials}

The datasets supporting the conclusions of this article are included within the article.

\section{Authors' contributions}

The author' contributions are as follows: Yue-Fa Fang was in charge of the whole trial; Lu-Quan Li wrote the manuscript; Lin Wang and Jia-Qiang Yao assisted with analyses.

\section{Competing interests}

The authors declare no competing financial interests.

\section{Authors' information}

Lu-Quan $\mathbf{L i}$, born in 1994, is currently a $\mathrm{PhD}$ candidate at School of Mechanical, Electronic and Control Engineering, Beijing Jiaotong University, China. He received his bachelor's degree from Beijing Jiaotong University, China, in 2017. His research interests include parallel mechanism design, walking robot.

E-mail: 18116017@bjtu.edu.cn

Yue-Fa Fang, born in 1958, is currently a professor at School of Mechanical, Electronic and Control Engineering, Beijing Jiaotong University, China. His main research interests include robotic mechanism, parallel robot and mechanical design.

E-mail: yffang@bjtu.edu.cn

Lin Wang, born in 1995, is currently a PhD candidate at School of Mechanical, Electronic and Control Engineering, Beijing Jiaotong University, China.

E-mail:18116022@bjtu.edu.cn

Jia-Qiang Yao, born in 1995, is currently a PhD candidate at School of Mechanical, Electronic and Control Engineering, Beijing Jiaotong University, China.

E-mail:20116013@bjtu.edu.cn

\section{References}

[1] H Makino, N Furuya. SCARA robot and its family. in: Proceedings 3rd International Conference on Assembly Automation, 1982: 433-444.

[2] P-L Richard, C M Gosselin, X Kong. Kinematic Analysis and Prototyping of a Partially Decoupled 4-DOF 3T1R Parallel Manipulator. Journal of Mechanical Design, 2007, 129(6): 611-616.

[3] E F Fichter. A Stewart Platform- Based Manipulator: General Theory and Practical Construction. The International Journal of Robotics Research, 1986, 5(2): 157-182.

[4] L-W Tsai. Robot Analysis. The Mechanics of Serial and Parallel 
Manipulators. [M]. John Wiley and Sons Ltd, 1999.

[5] J-P Merlet. Parallel Robots [M]. Springer Science \& Business Media, 2006.

[6] L-T Schreiber, C Gosselin. Schönflies Motion PARAllel Robot (SPARA): A Kinematically Redundant Parallel Robot With Unlimited Rotation Capabilities. IEEE/ASME Transactions on Mechatronics, 2019, 24(5): 2273-2281.

[7] V Nabat, M d 1 O Rodríguez, O Company, et al. Par4: very high speed parallel robot for pick-and-place. in: Proceedings 2005 IEEE International Conference on Intelligent Robots and Systems, IROS, 2005: 553-558.

[8] S krut, O Company, M Benoit, et al. I4: A new parallel mechanism for Scara motions. in: Proceedings Of the 2003 IEEE International Conference on Robotics \& Automation, 2003: 14-19.

[9] S Krut, O Company, V Nabat, et al. Heli4: A Parallel Robot for Scara Motions with a Very Compact Traveling Plate and a Symmetrical Design. Proceedings of the 2006 IEEE/RSJ International Conference on Intelligent Robots and Systems, 2006: 1656-1661.

[10] F Pierrot, O Company. H4: a new family of 4-dof parallel robots. in: Proceedings 1999 IEEE/ASME International Conference on Advanced Intelligent Mechatronics, 1999: 508-513.

[11] S Yang, T Sun, T Huang. Type synthesis of parallel mechanisms having 3T1R motion with variable rotational axis. Mechanism and Machine Theory, 2017, 109: 220-230.

[12] X Kong, C M Gosselin. Type Synthesis of 3T1R 4-DOF Parallel Manipulators Based on Screw Theory. IEEE Transactions on Robotics and Automation, 2004, 20(2): 181-190.

[13] V Rosenzveig, S Briot, P Martinet. Minimal Representation for the Control of the Adept Quattro with Rigid Platform via Leg Observation Considering a Hidden Robot Model. 2013 Ieee/Rsj International Conference on Intelligent Robots and Systems (Iros), 2013: 430-435.

[14] S Liu, T Huang, J Mei, et al. Optimal Design of a 4-DOF SCARA Type Parallel Robot Using Dynamic Performance Indices and Angular Constraints. Journal of Mechanisms and Robotics, 2012, 4(3): 031005.

[15] G Wu, Z Lin, W Zhao, et al. A four-limb parallel Schönflies motion generator with full-circle end-effector rotation. Mechanism and Machine Theory, 2020, 146.

[16] J Gallardo-Alvarado, R Rodríguez-Castro, P J Delossantos-Lara. Kinematics and dynamics of a 4- P RUR Schönflies parallel manipulator by means of screw theory and the principle of virtual work. Mechanism and Machine Theory, 2018, 122: 347-360.

[17] Q Meng, F Xie, X-J Liu. Conceptual design and kinematic analysis of a novel parallel robot for high-speed pick-and-place operations. Frontiers of Mechanical Engineering, 2018, 13(2): 211-224.

[18] F Xie, X-J Liu. Analysis of the kinematic characteristics of a high-speed parallel robot with Schönflies motion: Mobility, kinematics, and singularity. Frontiers of Mechanical Engineering, 2016, 11(2): 135-143.

[19] S Briot, I A Bonev. Pantopteron-4: A new 3T1R decoupled parallel manipulator for pick-and-place applications. Mechanism and Machine Theory, 2010, 45(5): 707-721.

[20] C Gosselin, M Isaksson, K Marlow, et al. Workspace and Sensitivity Analysis of a Novel Nonredundant Parallel SCARA Robot Featuring Infinite Tool Rotation. IEEE Robotics and Automation Letters, 2016, 1(2): 776-783.

[21] A Arian, M Isaksson, C Gosselin. Kinematic and dynamic analysis of a novel parallel kinematic Schönflies motion generator. Mechanism and Machine Theory, 2020, 147.

[22] $\mathrm{L} \mathrm{Xu}, \mathrm{Q}$ Chen, $\mathrm{L} \mathrm{He}$, et al. Kinematic analysis and design of a novel 3T1R 2-(PRR)2RH hybrid manipulator. Mechanism and Machine Theory, 2017, 112: 105-122.

[23] O Company, F Pierrot, V Nabat, et al. Schoenflies motion generator: A new non redundant parallel manipulator with unlimited rotation capability. 2005 Ieee International Conference on Robotics and Automation (Icra), Vols 1-4, 2005: 3250-3255.

[24] H Simas, R Di Gregorio. Position analysis, singularity loci and workspace of a novel 2PRPU Schoenflies-motion generator. Robotica, 2018, 37(1): 141-160.

[25] R Di Gregorio, M Cattai, H Simas. Performance-Based Design of the CRS-RRC Schoenflies-Motion Generator. Robotics, 2018, 7(3).

[26] C-C Lee, J M Hervé. Isoconstrained Parallel Generators of Schoenflies Motion. Journal of Mechanisms and Robotics, 2011, $3(2)$.

[27] P C Lee, J J Lee, C C Lee. Four Novel Pick-and-Place Isoconstrained Manipulators and Their Inverse Kinematics. Proceedings of the Asme International Design Engineering Technical Conferences and Computers and Information in Engineering Conference 2010, Vol 2, Pts $a$ and B, 2010: 1079-1088.

[28] L Kang, S-M Oh, W Kim, et al. Design of a new gravity balanced parallel mechanism with Schönflies motion. Proceedings of the Institution of Mechanical Engineers, Part C: Journal of Mechanical Engineering Science, 2016, 230(17): 3111-3134.

[29] P-C Lee, J-J Lee. Singularity and workspace analysis of three isoconstrained parallel manipulators with schoenflies motion. Frontiers of Mechanical Engineering, 2012, 7(2): 163-187.

[30] L Li, Y Fang, L Wang. Type synthesis of single-loop 3T1R-parallel mechanisms with a multi-DOF drive system. Mechanism and Machine Theory, 2021, 163: 104373.

[31] J Angeles. The Qualitative Synthesis of Parallel Manipulators. Journal of Mechanical Design, 2004, 126(4): 617-624.

[32] J Angeles, A Morozov, O Navarro. A novel manipulator architecture for the production of SCARA motions. Proceedings 2000 ICRA. Millennium Conference. IEEE International Conference on Robotics and Automation. Symposia Proceedings (Cat. No.00CH37065), 2000: 2370-2375.

[33] C Chen, T Gayral, S Caro, et al. A Six Degree of Freedom Epicyclic-Parallel Manipulator. Journal of Mechanisms and Robotics, 2012, 4(4): 041011.

[34] W Li, J Angeles. A Novel Three-Loop Parallel Robot With Full Mobility: Kinematics, Singularity, Workspace, and Dexterity Analysis. Journal of Mechanisms and Robotics-Transactions of the Asme, 2017, 9(5): 051003.

[35] P Karimi Eskandary, J Angeles. The dynamics of a parallel Schönflies-motion generator. Mechanism and Machine Theory, 2018, 119: 119-129.

[36] J Angeles, S e Caro, W Khan, et al. The Design and Prototyping of an Innovative Schoenflies Motion Generator. Part C, Journal of Mechanical Engineering Science, 2006, 200(C7): 935-944.

[37] P Karimi Eskandary, J Angeles. The virtual screw: Concept, design and applications. Mechanism and Machine Theory, 2018, 128: 349-358.

[38] P Karimi Eskandary, J Angeles. The translating П-joint: Design and applications. Mechanism and Machine Theory, 2018, 122: 361-370.

[39] T Harada, T Friedlaender, J Angeles. The Development of an Innovative Two-DOF Cylindrical Drive: Design, Analysis and 
Preliminary Tests. 2014 Ieee International Conference on Robotics and Automation (Icra), 2014: 6338-6344.

[40] F Pierrot, V Nabat, O Company, et al. Optimal Design of a 4-DOF Parallel Manipulator: From Academia to Industry. IEEE Transactions on Robotics, 2009, 25(2): 213-224.

[41] J M Herve. The Lie group of rigid body displacements, a fundamental tool for mechanism design. Mechanism and Machine Theory, 1999, 34(5): 719-730.

[42] J M Hervé. Analyse structurelle des mécanismes par groupe des déplacements. Mech. Mach. Theory, 1978, 13(4): 437-450.

[43] C Gosselin, J Angeles. Singularity analysis of closed-loop kinematic chains. IEEE Transactions on Robotics and Automation, 1990, 6(3): 281-290.

[44] D Zlatanov, I A Bonev, C M Gosselin. Constraint singularities of parallel mechanisms. Proceedings 2002 IEEE International Conference on Robotics and Automation, 2002: 496-502.

\section{Appendix}

Kinematic and dynamic parameters of the proposed Schönflies motion parallel robot used in the simulation are listed as follows:

$l=0.055 \mathrm{~m}, l_{11}=0.23 \mathrm{~m}, l_{12}=0.26 \mathrm{~m}, l_{13}=0.03 \mathrm{~m}, l_{21}=0.25 \mathrm{~m}$, $l_{22}=0.24 \mathrm{~m}, \quad l_{23}=0 \mathrm{~m}, \quad \mathrm{~m}_{\mathrm{L} 11}=0.326858 \mathrm{~kg}, \quad \mathrm{~m}_{\mathrm{L} 12}=0.245 \mathrm{~kg}$, $\mathrm{m}_{\mathrm{L} 21}=0.348 \mathrm{~kg}, \quad \mathrm{~m}_{\mathrm{L} 22}=0.21 \mathrm{~kg}, \quad \mathrm{~m}_{\mathrm{N} i 1}=0.074712 \mathrm{~kg}$, $\mathrm{m}_{\mathrm{N} i 2}=0.075153 \mathrm{~kg}, \mathrm{~m}_{\mathrm{B} i}=0.467 \mathrm{~kg} . \mathrm{m}_{\mathrm{O}}=0.193 \mathrm{~kg} . p_{1}=0.01 \mathrm{~m}$, $p_{2}=-0.01 \mathrm{~m}, \quad p_{13}=0.01 \mathrm{~m}, \quad p_{23}=0 \mathrm{~m}$, where symbol '-' represents that the rotation direction of the screw is contrary.

The positions of mass center of links are listed as $l_{11}{ }^{\prime}=0.084763 \mathrm{~m}, \quad l_{12}{ }^{\prime}=0.128414 \mathrm{~m}, \quad l_{21}{ }^{\prime}=0.093818 \mathrm{~m}$, $l_{22}{ }^{\prime}=0.107197 \mathrm{~m}$.

The inertia matrix of the link about its mass center, expressed in the link frame $\left\{\boldsymbol{L}_{i j}\right\}$ :

$$
\begin{aligned}
\mathbf{I}_{\mathrm{L}_{11}} & =\left[\begin{array}{ccc}
4.7143 & 0 & 6.0233 \\
0 & 200.45 & 0 \\
6.0233 & 0 & 202.14
\end{array}\right] \times 10^{-5} \mathrm{~kg} \cdot \mathrm{m}^{2}, \\
\mathbf{I}_{\mathrm{L}_{12}} & =\left[\begin{array}{ccc}
1.8143 & 0 & 1.3204 \\
0 & 190.96 & 0 \\
1.3204 & 0 & 191.59
\end{array}\right] \times 10^{-5} \mathrm{~kg} \cdot \mathrm{m}^{2}, \\
\mathbf{I}_{\mathrm{L}_{21}} & =\left[\begin{array}{ccc}
4.9282 & 0 & 6.6668 \\
0 & 248.09 & 0 \\
6.6668 & 0 & 249.92
\end{array}\right] \times 10^{-5} \mathrm{~kg} \cdot \mathrm{m}^{2}, \\
\mathbf{I}_{\mathrm{L}_{22}} & =\left[\begin{array}{ccc}
1.3764 & 0 & 0.7329 \\
0 & 122.71 & 0 \\
0.7329 & 0 & 123.41
\end{array}\right] \times 10^{-5} \mathrm{~kg} \cdot \mathrm{m}^{2}
\end{aligned}
$$

The inertia matrix of the screw about its mass center, expressed in the nut frame $\left\{\boldsymbol{S}_{i j}\right\}$ :

$$
\mathbf{I}_{\mathrm{S}_{i j}}=\left[\begin{array}{ccc}
423.34 & 0 & 0 \\
0 & 423.34 & 0 \\
0 & 0 & 0.8979
\end{array}\right] \times 10^{-5} \mathrm{~kg} \cdot \mathrm{m}^{2}(\mathrm{~A}-2)
$$

The inertia matrix of the nut about its mass center, expressed in the nut frame $\left\{\boldsymbol{N}_{i j}\right\}$ :

$$
\begin{aligned}
\mathbf{I}_{\mathrm{N}^{\mathrm{j}}} & =\left[\begin{array}{ccc}
1.6950 & 0 & 0 \\
0 & 1.6950 & 0 \\
0 & 0 & 1.5318
\end{array}\right] \times 10^{-5} \mathrm{~kg} \cdot \mathrm{m}^{2}, \\
\mathbf{I}_{\mathrm{N}_{2 j}} & =\left[\begin{array}{ccc}
1.7142 & 0 & 0 \\
0 & 1.7142 & 0 \\
0 & 0 & 1.5393
\end{array}\right] \times 10^{-5} \mathrm{~kg} \cdot \mathrm{m}^{2}
\end{aligned}
$$

The rotation matrix between the frame of each component and fixed frame $\{\boldsymbol{G}\}$ :

$$
\begin{aligned}
{ }^{G} \mathrm{R}_{\mathrm{o}} & =\left[\begin{array}{ccc}
\mathrm{c} \gamma & -\mathrm{s} \gamma & 0 \\
\mathrm{~s} \gamma & \mathrm{c} \gamma & 0 \\
0 & 0 & 1
\end{array}\right],{ }^{G} \mathrm{R}_{\mathrm{L}_{i j}}=\left[\begin{array}{ccc}
\mathrm{c} \theta_{i j} & -\mathrm{s} \theta_{i j} & 0 \\
\mathrm{~s} \theta_{i j} & \mathrm{c} \theta_{i j} & 0 \\
0 & 0 & 1
\end{array}\right], \\
{ }^{G} \mathrm{R}_{\mathrm{N}_{i j}} & =\left[\begin{array}{ccc}
\mathrm{c} \theta_{i 1} & -\mathrm{s} \theta_{i 1} & 0 \\
\mathrm{~s} \theta_{i 1} & \mathrm{c} \theta_{i 1} & 0 \\
0 & 0 & 1
\end{array}\right],{ }^{G} \mathrm{R}_{\mathrm{S}_{i j}}=\left[\begin{array}{ccc}
\mathrm{c} \psi_{i j} & -\mathrm{s} \psi_{i j} & 0 \\
\mathrm{~s} \psi_{i j} & \mathrm{c} \psi_{i j} & 0 \\
0 & 0 & 1
\end{array}\right]
\end{aligned}
$$




\section{Supplementary Files}

This is a list of supplementary files associated with this preprint. Click to download.

- Simulationvedio1.mp4

- Simulationvedio2.mp4 